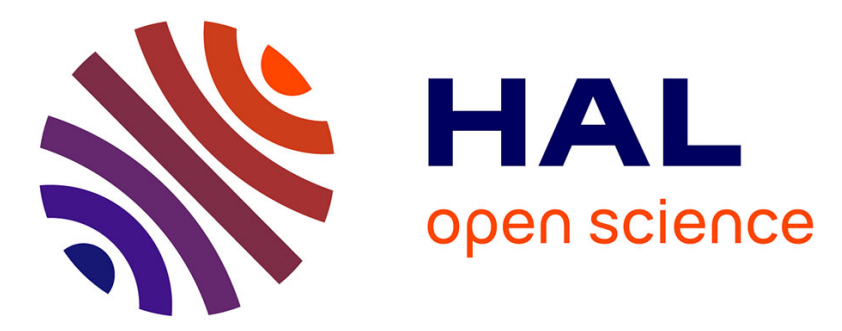

\title{
Performance of a biomass adapted to oncological ward wastewater vs. biomass from municipal WWTP on the removal of pharmaceutical molecules
}

Pierre Hamon, Philippe Moulin, Lionel Ercolei, Benoit Marrot

\section{- To cite this version:}

Pierre Hamon, Philippe Moulin, Lionel Ercolei, Benoit Marrot. Performance of a biomass adapted to oncological ward wastewater vs. biomass from municipal WWTP on the removal of pharmaceutical molecules. Water Research, 2018, 128, pp.193 - 205. 10.1016/j.watres.2017.10.037 . hal-02114290

\author{
HAL Id: hal-02114290 \\ https://hal.science/hal-02114290
}

Submitted on 29 Apr 2019

HAL is a multi-disciplinary open access archive for the deposit and dissemination of scientific research documents, whether they are published or not. The documents may come from teaching and research institutions in France or abroad, or from public or private research centers.
L'archive ouverte pluridisciplinaire HAL, est destinée au dépôt et à la diffusion de documents scientifiques de niveau recherche, publiés ou non, émanant des établissements d'enseignement et de recherche français ou étrangers, des laboratoires publics ou privés. 


\section{Accepted Manuscript}

Performance of a biomass adapted to oncological ward wastewater vs. biomass from municipal WWTP on the removal of pharmaceutical molecules

P. Hamon, P. Moulin, L. Ercolei, B. Marrot

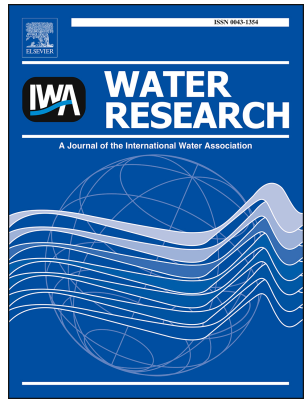

PII:

S0043-1354(17)30874-6

DOI:

10.1016/j.watres.2017.10.037

Reference: WR 13294

To appear in: Water Research

Received Date: 3 April 2017

Revised Date: 6 October 2017

Accepted Date: 17 October 2017

Please cite this article as: Hamon, P., Moulin, P., Ercolei, L., Marrot, B., Performance of a biomass adapted to oncological ward wastewater vs. biomass from municipal WWTP on the removal of pharmaceutical molecules, Water Research (2017), doi: 10.1016/j.watres.2017.10.037.

This is a PDF file of an unedited manuscript that has been accepted for publication. As a service to our customers we are providing this early version of the manuscript. The manuscript will undergo copyediting, typesetting, and review of the resulting proof before it is published in its final form. Please note that during the production process errors may be discovered which could affect the content, and all legal disclaimers that apply to the journal pertain. 


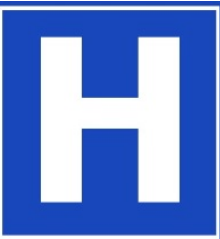

\section{Oncological} department

WASTEWATER WITH A HIGH CONCENTRATION OF MOLECULES
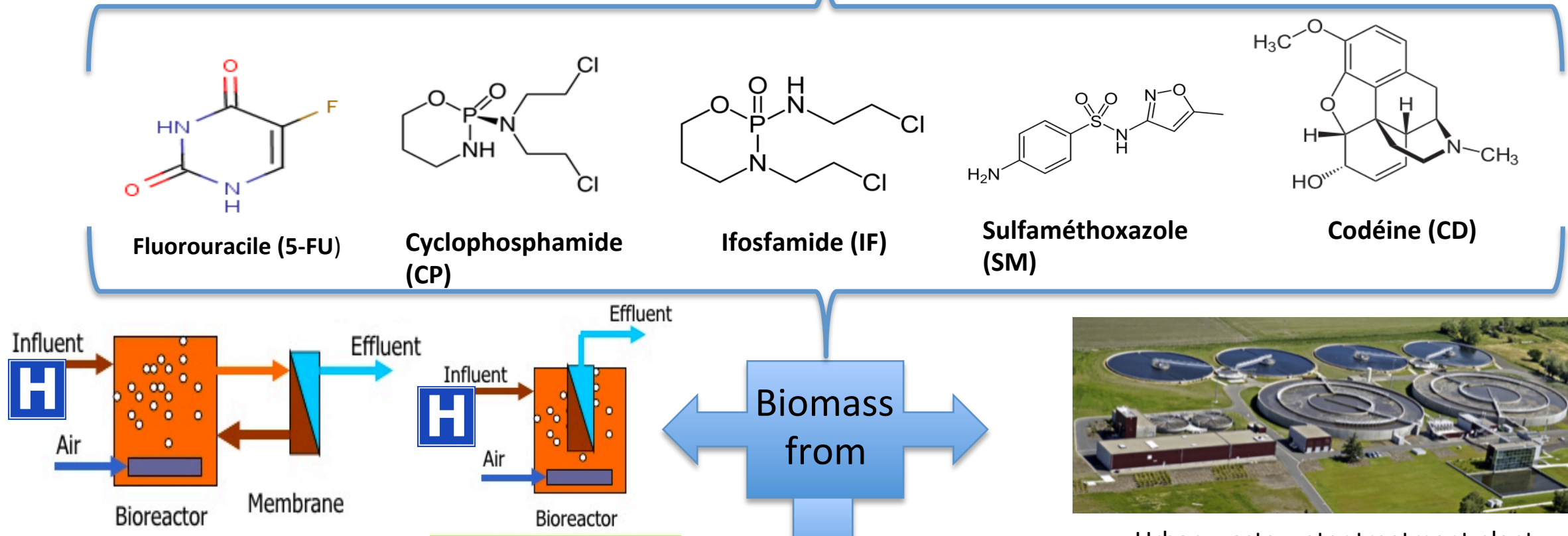

MBR adapted to oncological wastewater

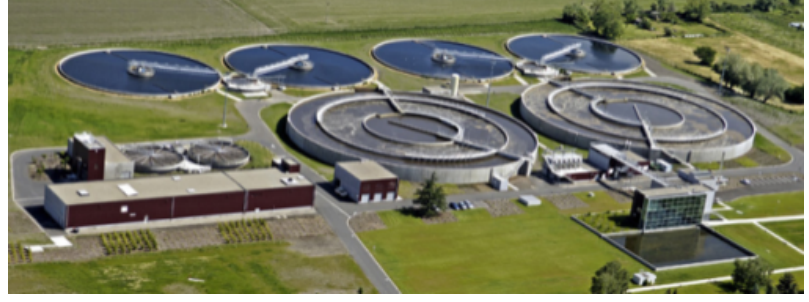

Urban waste water treatment plant

\section{Performance in terms of}

Biomass resistance

Processing capacity

Sorption or biotransformation

Removal of pharmaceutical molecules 


\title{
Performance of a biomass adapted to Oncological Ward Wastewater vs. biomass from
}

\section{municipal WWTP on the removal of pharmaceutical molecules}

\author{
P. HAMON $^{(1-2)}$, P. MOULIN ${ }^{(1 *)}$, L. ERCOLEI $^{(2)}$, B. MARROT $^{(1)}$
}

\section{${ }^{(2)}$ Société des Eaux de Marseille, 25 Rue Edouard Delanglade, 13006 Marseille, France}

4

(1) Aix Marseille Université, CNRS, Centrale Marseille, M2P2 UMR 7340, Equipe Procédés Membranaires (EPM), Europôle de l'Arbois, BP80, Pavillon Laennec, Hall C, 13545 Aix en Provence Cedex, France

*corresponding author: philippe.moulin@univ-amu.fr Tel.: +334429085 01, fax: +33442908515.

\section{Abstract}

The performance of a biomass adapted to Oncological Ward Wastewater (OWW) in a membrane bioreactor (MBR) was compared with that of a municipal WWTP, on the removal of pharmaceutical molecules and more specifically on their overall resistance and purifying ability in the presence of pharmaceutical cocktails. Sorption and biotransformation mechanisms on two antineoplastics, one antibiotic and a painkiller were evaluated. Sludge acclimated to OWW allowed for a $34 \%$ increase in the removal rate and in the minimum inhibition concentration. The percentage of the amounts of specific pharmaceutical compounds removed by biotransformation or by sorption were measured. These results are positive, as they show that the observed removal of 
18 pharmaceutical molecules by biomass acclimated to OWW can mostly be attributed to

19 developed biotransformation, unlike the biomass from the municipal WWTP for which

20 sorption is sometimes the only removal mechanism. The biotransformation kinetic and

21 the solid-water distribution coefficients in this study show good agreement with

22 literature data, even for much higher pharmaceutical concentrations in OWW.

23

24 Keywords

25 Pharmaceutical compounds; Acclimated sludge; pharmaceutical removal; sorption;

26 biotransformation 


\section{Introduction}

The removal of pharmaceutical residues in wastewater treatment plants (WWTP) by activated sludge is carried out through two mechanisms: biotransformation (biological removal and metabolization of the parent molecule) and sorption; photo transformation and air-stripping are negligible (POSEIDON 2006). The biotransformation of pharmaceutical compounds follows a pseudo-first order model (Joss et al., 2006) in a concentration range which does not inhibit biomass. The Hydraulic Retention Time (HRT) may therefore be optimized according to concentrations at process input and to the value of the $k_{i}$ biol constant of the pharmaceutical molecule. So the $k_{i}$ biol constant depends on the degradability of the compound but also on the composition of the sludge, which influences the mechanism of biodegradation of pharmaceutical compounds in several ways. Joss et al. (2006) classified pharmaceutical compounds into 3 groups, according to their constants (i) $k_{i}$ biol $<0,1$ L.gTSS ${ }^{-1} \cdot \mathrm{d}^{-1}$ : no significant transformation/removal through biodegradation; (ii) $0,1<k_{i}$,biol $<10$ L.gTSS $^{-1} \cdot \mathrm{d}^{-1}$ : partial removal (20\% to $90 \%$ ) and (iii) $k_{i}$ biol > 10 L.gTSS$^{-1} \cdot \mathrm{d}^{-1}$ : more than $90 \%$ transformation/removal via biodegradation. Their results show that only 4 out of the 35 pharmaceuticals molecules studied (estrone, estradiol, ibuprofen and paracetamol) could be removed by $90 \%$ through biotransformation but that this mechanism could be overestimated for a third of the compounds studied. It does not seem possible to conclude on the bio transformability of a pharmaceutical molecule because of the few exceptions that were obtained for antibiotics and anti-inflammatory agents. So the $k_{i}, b i o l$ constant must be determined experimentally. $\mathrm{pH}$, redox potential, stereochemical structure and the chemical structure of the sorbent and of the sorbed molecule may influence the effect of the sorption mechanism on the activated sludge (Kümmerer, 2009), be it through adsorption or absorption. Thus the influence of $\mathrm{pH}$ on the removal 
of ionizable micropollutants in a Membrane Bioreactor (MBR) was confirmed by applying an acid pH which modified the hydrophobicity of some compounds which are not inclined to sorption on the bacterial flocs at a neutral pH (Urase et al., 2005; Tadkaew et al., 2010). The solid-water partition coefficient $K_{D}$, also called Nernst coefficient, was then introduced as the most appropriated parameter representing the sorbed fraction of a molecule on suspended matter (Schwarzenbach et al., 2003; Ternes et al., 2004). The sorption of a compound is considered negligible for municipal WWTP if $K_{D}$ is smaller than $500{\mathrm{~L} . \mathrm{kg}_{\mathrm{TSS}}}^{-1}$ as it would represent less than $10 \%$ removal (Ternes et

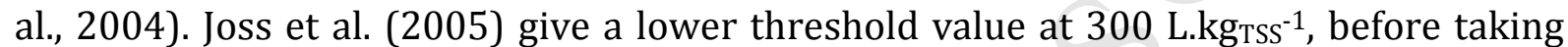
the sorption mechanism into account. Sipma et al. (2010) conclude that the sorption of pharmaceutical compounds on activated sludge is generally a minor removal mechanism, due to the low values of $K_{D}$ in pharmaceuticals. Numerous pharmaceutical molecules are hydrophilic, which a priori limits sorption phenomena. Nevertheless, very hydrophilic molecules, such as antibiotics from the fluoroquinolone class, are removed very efficiently through sorption due to electrostatic interactions (Göbel et al., 2007; Vieno et al., 2007). Out of 40 micropollutants that were studied in an MBR, the 14 very hydrophobic molecules were all removed at more than 85\% (Tadkaew et al., 2011). It is necessary to distinguish between the 2 mechanisms of pharmaceutical micropollutants removal in order to estimate the proportion transferred to the sludge, which would allow for an assessment of the environmental relevance of the removal procedure / disposal of excess WWTP sludge.

Moreover, the treatment process may influence the ability of the biomass to resist toxic charges, as Henriques et al. (2005-2007) state that some processes are more sensitive to inhibition: it is the case of activated sludge flocs, which boost the formation of small aggregates (such as MBR) and processes involving a high shear. In their study, 
respirometric tests on the biomasses of $2 \mathrm{MBR}$ revealed an inhibition 1.25 and two times greater than that of a conventional activated sludge process while in contact with chemical toxins, with MBR bacterial flocs smaller by $41 \%$.

The choice of treatment process configuration is very important in its ability to resist the presence of toxic material, as shear stress rate is different according to configuration. It is therefore expected that the MBR configuration may influence the ability of activated sludge to resist and to acclimate to a highly concentrated pharmaceuticals effluent. For this study, we decided to compare the performance of a biomass adapted to Oncological Ward Wastewater (OWW) with that of a municipal WWTP, on the removal of pharmaceutical molecules and more specifically on their overall resistance to the presence of pharmaceutical cocktails and the preservation of their purifying ability. Removal of one of the oncological ward's most consumed antineoplastics (5-FU) was quantified for both biomasses. Then removal of easily biodegradable substrate in the presence of pharmaceutical cocktails (antineoplastics and antibiotics) was measured for both biomasses in order to determine whether (i) adaptation to OWW permitted to increase resistance of the biomass to pharmaceuticals and whether (ii) one class of pharmaceuticals is more harmful than another to the performance of both biomasses. This objective arose from the different uses of antineoplastics and antibiotics in hospitals. While antineoplastics and antibiotics are administered continuously in oncologic wards, the antibiotics are given to prevent possible post-surgical infections and their concentrations in effluent can be strongly modified as a function of time and the number of patients. Hence it is assumed that the adaptation of the biomass to antibiotics is made all the more delicate by the occasional presence of concentration peaks in hospital effluents (OWW). Finally sorption and biotransformation mechanisms 
on two antineoplastics, one antibiotic and a painkiller were studied for both activated sludge.

\section{Equipment and methods}

\section{II.1. MBR and hospital effluents}

A pilot-scale membrane bioreactor was designed, built and set up underneath the oncological ward of the Timone hospital (Marseille, France). The MBR pilot was designed for treating 1 to $2 \mathrm{~L}^{-1} \mathrm{~h}^{-1}$ of hospital effluent from the oncological ward. The pilot has a maximum capacity of $60 \mathrm{~L}$, with an operating volume set at $32 \mathrm{~L}$. A $3.1 \mathrm{~kW}$ refrigeration unit allowed for regulation of activated sludge temperature at $25 \pm 2{ }^{\circ} \mathrm{C}$. OWW were kept in a storage tank with a maximum capacity of $200 \mathrm{~L}$ and were renewed every other day. First, OWW were sent into the denitrification tank (10.5 L) which was stirred through sludge recirculation carried out by a peristaltic pump. The dissolved oxygen concentration is continuously monitored in the denitrification reactor in order to check its zero value. The bacterial flocs were maintained in suspension without aerating the anoxic zone, which allowed the denitrification reaction to take place. A fraction of the recirculated sludge was transferred to the aerobic tank, which has a capacity of $21.5 \mathrm{~L}$, and in which the nitrification reaction took place. The hydraulic retention time (HRT) in both tanks was set through the adjustment of valves, which established $1 \mathrm{~h} / 2 \mathrm{~h}$ cycles in the anoxic and anaerobic tanks respectively. Aeration was performed by fine air bubbles delivered through four porous tubes connected to a compressor. This maintained oxygen concentration above $2 \mathrm{mg} . \mathrm{L}^{-1}$ and ensured the stirring of the aerobic tank. A centrifugal pump (B3, Motovario) located at the foot of the nitrification tank performed suction of the activated sludge towards the membrane module. Two acclimation 
campaigns to OWW were carried out: one using an external membrane bioreactor (eMBR) and another using an external submerged membrane bioreactor (sMBRe). The biomasses from the eMBR and sMBRe were acclimated to effluents from the Timone oncological ward (Marseille) for more than 150 days each (Hamon, 2014). The pipe collected wastewater from 6 rooms without dilution by the ward's other activities. Pretreatment consisted of maceration with a Saniflo (Plus Silence, SFA) and $0.5 \mathrm{~mm}$ cut off filtration. After a few days of operation sampling of the OWW was carried out at night in order to avoid dilution by shower drain water, thus an effluent with a higher ammonium content was obtained. In spite of the standardization of the sampling method, large fluctuations in COD and $\mathrm{N}-\mathrm{NH}_{4}{ }^{+}$concentrations were measured. COD and $\mathrm{N}-\mathrm{NH}_{4}{ }^{+}$concentrations were stabilized by feeding the MBR pilot with half OWW and half synthetic substrate during the second half of the first acclimation campaign in an eMBR configuration. Composition of the synthetic substrate which allowed for dilution of the polluting charge specific to OWW was determined using the average COD (800 mg.L-1 as sugar $\left.\mathrm{C}_{6} \mathrm{H}_{12} \mathrm{O}_{6}\right)$ and $\mathrm{N}-\mathrm{NH}_{4}^{+}\left(31 \mathrm{mg} \cdot \mathrm{L}^{-1}\right.$ as $\left.\left(\mathrm{NH}_{4}\right)_{2} \mathrm{SO}_{4}\right)$ concentrations, which were measured over a two-month period. Concentrations in mineral salts were set according to literature (Han et al., 2005; Barrioz-Martinez, 2006): C/N/P ratio of the synthetic effluent was $100 / 4 / 2$. In both MBR configurations the retentate was returned to the nitrification tank while the permeate was sent back to the oncological ward waste water pipe. The features of both MBR, of the acclimation parameters and of the activated sludge are listed in table 1. 
The three most consumed antineoplastics in the oncological ward of the Timone hospital are among the seven antineoplastics on the French national agency of sanitary safety of food, environment and work (Anses) list: ifosfamide (IF), fluorouracil (5-FU) and cyclophosphamide (CP). Fluorouracil was analyzed by the pharmacology and toxicokinetics laboratory of the Timone hospital (Marseille, France). Ifosfamide, cyclophosphamide, codeine and sulfamethoxazole were analyzed by the Ianesco laboratory (Institut d'Analyses et d'Essais en Chimie de l'Ouest, Poitiers, France). This laboratory is COFRAC-certified to analyze the specific molecules studied in our paper. The COFRAC accreditation certifies the technical competence of testing and calibration laboratories to perform specific tasks. The procedure for dosing 5-FU in blood plasma was successfully applied to OWW and treated water. 5-FU was analyzed with HPLC-UV (254 nm). The limit of quantification was $5 \mu \mathrm{g} . \mathrm{L}^{-1}$. The detection limits were obtained with several injections of compounds from 1 to $10 \mu \mathrm{g} \cdot \mathrm{L}^{-1}$. An accurate detection and repeatability were obtained from the concentration at $5 \mu \mathrm{g} . \mathrm{L}^{-1}$. In detail, the analytical system was divided into three parts: (A) a mobile phase composed of $0.05 \mathrm{M}$ monopotassium phosphate $\left(\mathrm{KH}_{2} \mathrm{PO}_{4}\right)$ was adjusted to $\mathrm{pH} 3$ with orthophosphoric acid and filtration at $0.2 \mu \mathrm{m}$. (B) $500 \mu \mathrm{L}$ of the sample to be analyzed was acidified with $20 \mu \mathrm{L}$ of $5 \%$ orthophosphoric acid; ibromouracil $\left(50 \mathrm{~mL}, 10 \mu \mathrm{g} \cdot \mathrm{mL}^{-1}\right)$ was added. The sample was extracted with $6 \mathrm{~mL}$ of n-propanol/diethylether 10:90 (v:v), mixed with an automatic vortex for 10 minutes before centrifugation for 15 minutes at $3000 \mathrm{~g}$ at $4^{\circ} \mathrm{C}$. The organic phase was sampled and evaporated in a water bath under nitrogen. The dry residue was recovered in $100 \mu \mathrm{L}$ of mobile phase and was centrifuged for 4 minutes. (C) The samples were analyzed by HPLC-UV: 7 solvent samples were injected for calibration (the 7 samples covered the whole concentration range), then the samples to be analyzed were injected, and finally 3 samples were injected for quality control. The four 
remaining molecules (cyclophosphamide, ifosfamide, sulfamethoxazole and codeine) were analyzed simultaneously by liquid chromatography combined with tandem mass spectrometry (LC/MS-MS). Detection limits were first estimated by calculation by injecting a low-concentration standard solution: the limit of detection is at least equal to 3 times the background noise and the limit of quantification is, to a minimum, equal to 10 times the signal of the background noise. The quantification limits were controlled by injecting a standard solution at this given concentration. Then real samples were doped at this given concentration in order to assess the accuracy and reliability of the analytical method. The limit of quantification of the method was $2.5 \mu \mathrm{g} . \mathrm{L}^{-1}$. The LC/MSMS was calibrated with a $200 \mathrm{mg} . \mathrm{L}^{-1}$ solution of our molecules of interest in methanol. A calibration range of $0,1,2.5,10,30,50$ and $100 \mu \mathrm{g} . \mathrm{L}^{-1}$ in ultrapure water / methanol $(80 / 20)$ was obtained by diluting the deuterated internal standards to $30 \mu \mathrm{g} \cdot \mathrm{L}^{-1}$ (sulfamethoxazole-D4, diclofenac-D4, ketoprofenD4 and caffeine). In detail, the analytical system used was composed of an AGILENT 1100 HPLC equipped with a high pressure pump, an automatic injector (thermostated by Peltier effect) and a SCIEX, API400 tandem mass spectrometer. Quantification was carried out with a calibration in solutions containing internal standards. The analytical conditions were: (i) an analytical column: ZORBAX Eclipse Plus C18 $(100 \mathrm{~mm} \times 2.1 \mathrm{~mm} \times 3.5 \mu \mathrm{m})$ with guard pre-column ZORBAX Eclipse Plus C18 (5 $\mu \mathrm{m}$ x $12.5 \mathrm{~mm}$ ). (ii) The solvent gradient parameters were set through two channels: channel A: ultra-pure water with $0.1 \%$ formic acid and channel B: methanol, with a flow rate of $0.35 \mathrm{~mL} \cdot \mathrm{min}^{-1}$. The solvent gradient was modified at $0-4 / 12 / 16 / 20 / 24 / 25 / 40 \mathrm{~min}$ with the respective ratios (A-B) 95-5/7030/30-70/2-98/1-99/0-100/95-5/95-5\%. The injected volume was $20 \mu \mathrm{L}$ and the oven temperature was $25^{\circ} \mathrm{C}$. The electrospray ionization mode (positive-mode Turbo-V) was positive mode (ion formation $[\mathrm{M}+\mathrm{H}]^{+}$mostly but also potentially $\mathrm{Na}^{+}$or $\mathrm{K}^{+}$adducts). The 
de-solvation temperature, the acquisition mode, the duration of the MRM windows and the duration of analysis were respectively $550^{\circ} \mathrm{C}, \mathrm{MRM}, 200 \mathrm{~s}$ and 44 minutes. The retention times for codeine, sulfamethoxazole, ifosfamide and cyclophosphamide were respectively 5.4/8.5/10.5/11 min. Prior to analysis, wastewater was decanted then filtered on a $0.45 \mu \mathrm{m}$ porosity filter. Removal of the coarsest solid materials should not lead to under-estimating the pharmaceutical concentration in $\mathrm{OWW}$, as the selected pharmaceuticals are excreted solely through the urinary tract and are hydrophilic. Thus sorption on TSS of OWW is negligible. The analytical LOQ might seem high regarding pharmaceutical concentration in municipal wastewater but is satisfying regarding the oncological ward wastewater which was investigated.

\section{$\underline{\text { II.3 Pharmaceutical cocktails }}$}

The influence of various pharmaceutical cocktails on the performance of both biomasses (acclimated to OWW and municipal WWTP) was assessed by using the kinetics of degradation of easily degradable substrates (COD, $\mathrm{NH}_{4}^{+}$) in a batch reactor. The pharmaceutical cocktails were prepared using hospital pharmaceuticals. The composition of the antineoplastics cocktail was based on the maximum concentration of 5-FU found in OWW during the acclimation period of the biomass, i.e. $1287 \mu \mathrm{g} . \mathrm{L}^{-1}$, on the metabolization rate of each pharmaceutical and on the maximum quantity consumed in the oncological ward unit to which the MBR was connected. The concentrations thus calculated are shown in Table 2.

$$
[\text { pharmaceutical }]=[5-F U]_{\text {max }} \cdot \frac{n_{\text {pharmaceutical }}}{n_{5-F U}} \cdot \frac{1-\tau_{\text {pharmaceutical }}}{1-\tau_{5-F U}} \quad \text { Eq. } 1
$$


221

222

223

224

225

226

227

228

229

with:

$[5-F U]_{\text {max }}$ : Maximum concentration in 5-FU detected in OWW during the first experimental campaign $\left(\mu \mathrm{g} \cdot \mathrm{L}^{-1}\right)$

$\mathrm{n}_{\text {pharmaceutical: annual consumption of the pharmaceutical in the unit (mg.year-1) }}$

$\mathrm{n}_{5-\mathrm{FU}}$ : annual 5-FU consumption in the unit (mg.year-1)

1- $\tau_{\text {pharmaceutical: }}$ non-metabolized pharmaceutical rate $(-)$

1- $\tau_{5-\mathrm{FU}}$ : non-metabolized $5-\mathrm{FU}$ rate $(-)$

The concentrations of the antibiotics cocktail were defined arbitrarily in order to obtain a total concentration in the same order of magnitude as that of the antineoplastics. Thus the concentration of each of the ward's four most consumed antibiotics was set at 1 mg.L-1 (Table 2).

It should be noted that these cocktails do not in any way represent the average or the maximum concentrations that could be detected in OWW. Five original COD concentrations plotted to the quantity of TSS were tested for each "type of biomass pharmaceutical cocktail" pair: $0.1-0.2-0.5-1-3$ gCOD.gTSS -1 . Total duration of the tests was 4h. However, the duration that was used to calculate the maximum degradation velocity varied according to original concentrations and corresponded to the linear degradation velocity of the COD.

\section{II.4 Sorption and biotransformation tests}

The technique to inhibit activated sludge must be adapted to sorption tests: it must allow for complete inhibition of the biotransformation mechanism and for preservation 
of the structural integrity of the activated sludge. Prior to sorption text, it was necessary to determine the most suitable activated sludge inhibition technique for carrying out these tests in order to ensure the consistency of batch tests with sorption phenomenon in the MBR: gas purging is the only technique that does not affect the structure of the biomass (Hamon et al. 2014). Moreover, this inhibition is very easily implemented and the inhibition state is reached immediately, as the concentration in dissolved oxygen drops down almost instantaneously to zero. The quantity of the selected pharmaceuticals, which were removed thanks to the sorption mechanism was evaluated for the activated sludge from the sMBRe pilot and from the municipal WWTP of Rousset (France). The sorption tests were carried out over $4 \mathrm{~h}$ as this duration allows ifosfamide and cyclophosphamide to reach sorption equilibrium, whatever the origin of the activated sludge (Seira, 2013). Sorption equilibrium of sulfamethoxazole was reached in 2h (Yang et al., 2011). There is no available data concerning codeine. Activated sludge filtered with coffee filters (average pore size $100 \mu \mathrm{m}$ ) was re-suspended with distilled water, so as not to use the supernatant from the sMBRe pilot, as it was likely to contain the selected pharmaceuticals at considerable concentrations, which could distort results. Activated sludge concentration in TSS was brought down to 4 g. $\mathrm{L}^{-1}$ using coffee filters. Sorption tests were performed on pharmaceutical cocktails in 4 different original concentrations close to $100-250-500$ and $1000 \mu \mathrm{g} \cdot \mathrm{L}^{-1}$. The original measured concentrations were slightly different but in the correct order of magnitude. Thus, to allow for easier reading, results are presented according to that concentration factor (1 - 2.5 - 5 and 10). Reductions and $\mathrm{K}_{\mathrm{D}}$ values were calculated using actual original concentrations. The activated sludge was placed in anaerobic conditions. Water was deoxygenated with dinitrogen, the pharmaceuticals were introduced and the initial sample was taken. Sorption tests were carried out in closed $200 \mathrm{~mL}$ brown glass vials 
filled completely and slightly stirred to ensure homogeneous mixing and avoid sedimentation of sludge particles. The null value of the dissolved oxygen was checked once every hour during tests. In biotransformation tests degradation kinetics of the selected pharmaceuticals were performed in brown glass vials, aerated over $4 \mathrm{~h}$, with sludge acclimated to OWW and WWTP sludge. Similarly to sorption tests, activated sludge concentration in TSS was brought down to 4 g.L-1 . Filtered sludge was resuspended with distilled water. The initial concentrations of the pharmaceutical cocktails were identical to that of the sorption tests, i.e. close to the targeted concentrations $100-250-500$ and $1000 \mu \mathrm{g} \cdot \mathrm{L}^{-1}$, and allowed us to respect the concentration factor $1-2.5-5$ and 10 .

\section{Results}

\section{III.1. Removal Performance}

\section{III.1.1.5-FU}

During the acclimation phase, 5-FU was almost consistently detected in OWW at concentrations up to $1287 \mu \mathrm{g} . \mathrm{L}^{-1}$ (minimum $49.6 \mu \mathrm{g} . \mathrm{L}^{-1}$ / average $440 \mu \mathrm{g} . \mathrm{L}^{-1} / 150$ days). These concentrations are very high compared with those measured in previous research: between 11.5 and $122 \mu \mathrm{g} . \mathrm{L}^{-1}$ for Mahnik et al. (2007) and between 35 and 92 ng. $\mathrm{L}^{-1}$ for Kosjek et al. (2013). The permeate samples which were analyzed show good removal of 5-FU by acclimated activated sludge, as reductions are above $90 \%$ in spite of high initial concentrations, sometimes greater than $1 \mathrm{mg} \cdot \mathrm{L}^{-1}$. Specific degradation velocity seems relatively proportional to the 5-FU initial concentration (pseudo-first order) (Figure 1). If the $\mathrm{V}_{\text {specificmBR }}>\mathrm{LOQ}$ and $\mathrm{V}_{\text {specificmBR }}<\mathrm{LOQ}$, the velocity was calculated from the value of the measured concentration and from the value of the LOQ 
respectively. Removal of 5-FU was assessed during similar research on treatment of OWW in an Austrian hospital using MBR (Mahnik et al., 2007). Results proved similar, with total removal of 5-FU, as 5-FU could no longer be quantified at process output. In the present study and even if the LOQ can be considered to be high, the concentrations in the effluent are so high that removal is always higher than $95 \%$. Obviously, each removal rate is calculated from specific measured data. By using batch degradation tests with radiolabeled compounds Mahnik et al. (2007) noticed total 5-FU removal from the liquid phase and negligible sorption onto the activated sludge, ranging from 2 to $5 \%$. Thus 5-FU is almost totally removed by biotransformation. The capacity of 5-FU to be biotransformed at low and high concentrations had already been shown by some authors (Kiffmeyer et al., 1998 ; Yu et al., 2006). However, these results were obtained by conducting tests on high concentrations which do not reflect the actual situation, as there might be an inhibitory effect and the analytical methods used were sometimes unsuitable (measurement of COD or of produced $\mathrm{CO}_{2}$ ). Thus Kümmerer (1997) observed contradictory results: he found no biotransformation of 5-FU for very high 5-FU concentrations ( 9 and 850 mg.L $\mathrm{L}^{-1}$ ). In this present study, degradation kinetics for 5-FU were performed on sludge from the municipal WWTP and on sludge acclimated to OWW in batch reactors for 5 initial concentrations: 50 - $1000 \mu \mathrm{g} \cdot \mathrm{L}^{-1}$. The kinetics were performed over $21 \mathrm{~h}$ so as to match the HRT of the eMBR pilot at the time of sampling. The sludge from the municipal WWTP was adjusted to the concentration of the acclimated sludge, i.e. 4.1 g.L-1. Whatever the concentration, 5-FU reduction was always slightly greater for acclimated sludge than for sludge sampled from municipal WWTP. In that concentration range the activated sludge from municipal WWTP also seemed very efficient for the removal of 5 -FU, as the minimum reduction was always greater than 
80\%. 5-FU reductions by both types of sludge, as well as associated specific degradation velocities are presented in Figure 2.

Just as with sludge acclimated to OWW, the higher the initial concentration, the greater the reduction was, which shows that the concentration range, which was tested (50$1000 \mu \mathrm{g} \cdot \mathrm{L}^{-1}$ ) was lower than a possible inhibition threshold; the kinetics remained pseudo-first order. Acclimation to OWW allowed the biomass to be slightly more efficient at initial low concentrations $\left(50-200 \mu \mathrm{g} . \mathrm{L}^{-1}\right)$. This improvement is minor as 5FU proved to be a very easily removable molecule. Thus the specific removal velocities of 5-FU were almost the same: $0.0115 \mathrm{~g}_{\mathrm{TSS}^{-1}} \mathrm{~h}^{-1}$ for the acclimated sludge and $0.0114 \mathrm{~g}_{\mathrm{TSS}}{ }^{-}$ ${ }^{1} \cdot \mathrm{h}^{-1}$ for the municipal WWTP. However it is very important to note that in spite of the numerous pharmaceuticals, metabolites and cleaning products contained in the OWW which was used for acclimation, the acclimated biomass proved to be at least as efficient as the WWTP sludge, which only removed 5-FU during those tests. Nevertheless the kinetics study allowed for identification of a few behavioral differences in both types of sludge. The degradation kinetic constants $\mathrm{k}_{\text {biol }}$ were calculated between $\mathrm{t}=15 \mathrm{~min}$ and $\mathrm{t}=90 \mathrm{~min}$ as the term $\ln \left(\mathrm{C} / \mathrm{C}_{0}\right)$ is linear in that range, thus confirming that the degradation kinetics is pseudo-first order for the first 90 minutes (Figure 3).

The evolution of the degradation constant $\mathrm{k}_{\text {biol }}$ shows that acclimation at the source allows for faster removal of 5-FU. Thus an average 34\% increase was reached for the acclimated sludge, compared with WWTP sludge. The variation of $\mathrm{k}_{\text {biol }}$ constants shows that WWTP reached a threshold, while the $\mathrm{k}_{\text {biol }}$ constants continue to evolve beyond $1000 \mu \mathrm{g} \cdot \mathrm{L}^{-1}$ for the acclimated sludge. Hence, it seems that the minimum inhibition concentration is lower for WWTP sludge than for sludge acclimated to OWW in the MBR. 


\section{III.1.2. Performance with pharmaceutical cocktails}

342 The influence of antineoplastics and antibiotics cocktails was quantified in the biomass acclimated to OWW and in a biomass from a municipal WWTP, by monitoring the

degradation of an easily biodegradable substrate. Specific degradation velocities of the COD were calculated for each "type of biomass - pharmaceutical cocktail" configuration and were represented according to the COD concentration plotted to the amount of TSS (Figure 4).

On Figure 4, positive and negative velocities respectively show COD degradation and an inhibitory effect exerted by pharmaceuticals. Non-acclimated WWTP sludge (Rousset, France) proved to be totally impacted by the presence of pharmaceutical cocktails: degradation velocity of the COD was zero at low concentrations and even became negative for high charges. A negative degradation velocity means that the presence of pharmaceuticals triggered cell lysis of activated sludge. Conversely, positive COD degradation velocities were measured for sludge acclimated to OWW, which means that it retains a capacity for purification in the presence of pharmaceuticals. However, COD degradation velocities were slower than that of the control group without pharmaceuticals, indicating that pharmaceutical cocktails still partially inhibit the performance of the biomass, which would be logical given the high concentrations used in the cocktail. Optimal degradation velocity was around 0.2 gCOD.gTSS$^{-1}$ for the acclimated sludge. An inhibition of COD degradation by pharmaceutical materials was observed from 0.1 gCOD.gTSS $^{-1}$ for the sludge in sole presence of the antineoplastic cocktail and from 0.2 gCOD.gTSS $^{-1}$ for the antineoplastic cocktail with antibiotics. Thus inhibition seems stronger for the antineoplastic cocktail on its own than for the combination of antineoplastic and antibiotic cocktails. This surprising observation could be due to (i) interactions between antineoplastics and antibiotics, which brought about a 
decrease in total pharmaceutical toxicity, or (ii) to the absence of toxicity of the antibiotics cocktails on acclimated sludge, hence the differences observed in specific removal velocities of the COD would be due only to experimental uncertainties (COD measurement precision). A contrasting behavior was observed for the municipal WWTP sludge. The antineoplastic cocktail in the presence of antibiotics triggered a more pronounced cell lysis than the sole antineoplastic cocktail, showing that antibiotics have a bactericidal effect on non-acclimated activated sludge. Thus the acclimated biomass acquired resistance to the tested antibiotics and may have been able to metabolize them partially. These results clearly demonstrate that biomass acclimation allowed for the development of capacities of high resistance to antineoplastics and antibiotics, since, at low charge, the sludge developed in the hospital MBR was only slightly affected by their presence.

\section{III.2. Removal mechanisms of the selected pharmaceuticals}

\section{III.2.1 Sorption}

Degradation tests in a batch reactor were performed so as to determine the influence of each of the two removal mechanisms coupled with the purifying biomass: sorption and biotransformation. These tests must show whether the apparent removal with sludge acclimated to OWW is mainly linked to a pollutant transfer from the liquid to the solid phase, or whether there is a biological metabolization by bacteria from the purifying biomass. Lastly, these tests were also carried out using municipal WWTP activated sludge from Rousset, so as to quantify the improvement brought by acclimation of sludge to OWW.

Sorption of the selected pharmaceuticals seemed relatively low for the antineoplastics molecules on the activated sludge of the sMBRe hospital pilot and for the municipal 
WWTP, as it turned out to be lower than 10\% (Figure 5a). Although its sorption remained very low, ifosfamide seems to have more affinities with sorption than cyclophosphamide, which is coherent with Seira's results (2013). Sulfamethazole was removed a few percent more than antineoplastics for both types of sludge, but its sorption remained limited as its removal reached a maximum $13 \%$ for sludge acclimated to OWW. Codeine seems to have much more pronounced sorption affinities, since its removal through sorption reached up to $30 \%$ for WWTP sludge. Whichever sludge was used, the proportion of sorption of pharmaceuticals tended to decrease as its initial concentration increased, because of a constant number of sorption sites on bacterial flocs for a larger amount of pollutant.

Thus apparent removal of cyclophosphamide, ifosfamide and sulfamethazole by acclimated sludge may be attributed to biotransformation.

Although transfer of pollutant from the liquid phase to sludge appears limited, the very high concentrations in pharmaceuticals in OWW may include significant amounts of pharmaceuticals sorbed onto the sludge of an MBR treating these OWW. These amounts, calculated from average concentrations measured in OWW and from corresponding concentration factors, show that ifosfamide and sulfamethazole might be present in high concentrations in MBR sludge and should be taken into account when choosing the appropriate treatment method for excess sludge (Table 3).

The evolution of distribution coefficients $K_{D}$ according to the concentration factor is logically identical to that of reduction through sorption (Figure 5b). The selected pharmaceuticals have low distribution coefficients $\mathrm{K}_{\mathrm{D}}$. $\mathrm{K}_{\mathrm{D}}$ was smaller than 40 L.kgTSS${ }^{-1}$ for CP, IF and SM and smaller than $120 \mathrm{~L} . k g T S S^{-1}$ for CD in municipal WWTP. Joss et al. (2005) claimed that for a value of $K_{D}$ smaller than 300 L.kgTSS$^{-1}$ sorption of a compound is negligible and its removal may be assessed using input and output concentrations. 
According to Ternes et al. (2004) sorption may be considered as a significant removal mechanism at a threshold value of 500 L.kgTSS$^{-1}$. Even though this seems justified for both antineoplastics, SM sorption represents more than $10 \%$ of removal for acclimated sludge, and more importantly, sorption of CD allows for a removal above $30 \%$. These observations match Seira's (2013), who noted that low values of $\mathrm{K}_{\mathrm{D}}$ could not be systematically neglected since sometimes significant removal could occur even for molecules presenting low $\mathrm{K}_{\mathrm{D}}$. He proposed to highlight the particle concentrations associated to any suggestion of $K_{D}$ limit value from which sorption may be considered negligible.

Sorption of CP, IF and SM proved to be in the same order of magnitude for both tested activated sludge. The nature of the sludge could have significantly influenced the sorption affinities of a compound, but comparison between the sludge acclimated to OWW and that of the Rousset WWTP provided no evidence of this. This was probably due to the fact that the MBR of the WWTP and that of the MBR which was used for acclimation had the same configuration (submerged external membrane bioreactor). Another factor could be the origin of the sludge which was used as a base for acclimation, which came from the Rousset WWTP. Comparing several studies would be difficult because of differences in experimental procedures and in the nature of the sludge (Table 4).

$\mathrm{K}_{\mathrm{D}}$ coefficients of both antineoplastics (CP and IF) found in the literature are generally low (Seira, 2013; Ternes et al., 2004). High values of $\mathrm{K}_{\mathrm{D}}$ for CP of 794.3 L.kgTSS-1 (Delgado, 2009) and of 111.4 L.kgTSS$^{-1}$ (Zaviska, 2013) could be due to the thermic inhibition technique used, which completely breaks down the biomass (Hamon et al., 2014). For activated sludge from an MBR pilot, Seira (2013) obtained similar results to those of this study, with a KD of $15 \mathrm{~L} . k g T S S^{-1}$ for CP and of $22 \mathrm{~L} . k g T S S^{-1}$ for IF. It should 
be noted that Seira's study measured the most pronounced sorption of CP and IF for eMBR sludge. This was attributed to the smaller-sized flocs, which provided more sorption sites to compounds. $\mathrm{K}_{\mathrm{D}}$ coefficients of SM found in the literature seem very heterogeneous as they range from 3.2 to 370 L.kgTSS$^{-1}$. These differences could be explained by the nature of the activated sludge and by the inhibition techniques that were used, but also by SM photosensitivity (Hörsing et al., 2011), which is negligible in this study since sorption tests were carried out in brown glass vials. Average values of 34.1 L.kgTSS $^{-1}$ measured in this study for sludge acclimated to OWW and of 21.4 L.kgTSS $^{-1}$ for Rousset WWTP sludge were in the same order of magnitude as $\mathrm{K}_{\mathrm{D}}$ measured in the studies of Abbeglen (2009) for MBR sludge and Yang et al. (2011) for conventional WWTP sludge. Significant differences were observed for values of $\mathrm{K}_{\mathrm{D}}$ obtained for CD. Again, these differences could be due to the inhibition techniques that were used and/or to the nature of the activated sludge. It should also be noted that the sorption assessed in this study is competitive as pharmaceuticals were added as a cocktail, while the results of some studies in the literature are sorption values of isolated compounds.

Although sorption of the selected pharmaceuticals may not be totally ignored, it proved to be a minor removal mechanism for acclimated sludge, except for codeine, which could be removed through sorption in proportions ranging around 30\%.

\section{$\underline{\text { III.2.2. Biotransformation }}$}

Concerning biotransformation tests, a definite improvement in the total removal of the 4 pharmaceuticals was observed with sludge acclimated to OWW (Figure 6). The initial concentration was analysed. Except for codeine, which was always removed very 
efficiently whatever the concentration factor, total removal of pharmaceuticals with acclimated sludge seemed to increase with their initial concentration. Conversely and except for ifosfamide, removal with sludge from the municipal WWTP seemed to stagnate when initial concentration increased. Capacities for biotransformation were developed by sludge acclimated to OWW while removal of selected pharmaceuticals from the Rousset municipal WWTP sludge was mainly due to a sorption mechanism, as the following ratio shows:

$\frac{\text { Biotransformation }}{\text { Sorption }}$ smaller than 1 (Table 5).

In accordance with literature, the biotransformation measured for the 2 antineoplastics CP and IF by municipal WWTP sludge proved to be low, even zero (Kümmerer et al., 1997; Buerge et al., 2006). Removal of CD and SM through biotransformation in the Rousset WWTP sludge was low, as it was in the order of $8 \%$ in $4 \mathrm{~h}$. Total removal after 4 h seems to confirm partial removal of these two pharmaceuticals, as mentioned in the literature. The stagnation of removal which was observed for the municipal WWTP sludge could show the inhibition effect exerted by the most concentrated pharmaceutical cocktails. Besides, the $1000 \mu \mathrm{g} . \mathrm{L}^{-1}$ cocktail of each of these pharmaceuticals seemed to trigger a very strong inhibition, as a significant decrease in the reduction of $\mathrm{CD}$ was noted. Thus increase in the removal of $\mathrm{CP}$ and IF for the most concentrated cocktail could be due to the sorption of these molecules onto soluble microbial products which were released during a possible cell lysis brought about by the pharmaceutical cocktails in the non-acclimated municipal WWTP sludge. The IANESCO Laboratory is certified and these conclusions are validated by the results of analyses. These batch reactor tests confirm the correct reductions with $43 \%$ maximum removal 
for SM and around 70\% for CD in only $4 \mathrm{~h}$ (Figure 6). These results agree with those measured in the supernatant of the MBR during the acclimation period of the sludge. However, maximum removal of $\mathrm{CP}$ at $36 \%$ and of IF at $38 \%$ in that reduced time scale seems better than the removal obtained in the MBR. This could stem from the nature of the substrate, which was far less rich and complex than real OWW, and from the initial absence of these molecules in the supernatant, which was not the case in the MBR. It should also be noted that exclusively aerobic conditions (applied in batch reactors) are known to favor degradation of micropollutants as opposed to aerobic/anoxic processes (applied in the MBR) (Suarez et al., 2010), even if a $4 \mathrm{~h}$ test remains far shorter than the HRT of the MBR. Although these removals are incomplete, it should be noted that the differences in the associated concentrations are substantial since they are in the order of $700 \mu \mathrm{g} . \mathrm{L}^{-1}$ for CD and $400 \mu \mathrm{g} . \mathrm{L}^{-1}$ for SM, CP and IF.

These removals were obtained without adding a cosubstrate in the batch reactors. Thus actual biotransformation of the selected pharmaceuticals could be achieved through a direct metabolic pathway. Seira (2013) did not observe any biotransformation of CP and IF without adding a cosubstrate, but the concentrations tested in his study, respectively 6 and $2 \mu \mathrm{g} . \mathrm{L}^{-1}$, were much lower than those of the present study (100 to 1,000 $\mu \mathrm{g} . \mathrm{L}^{-1}$ ). The higher concentrations used here are representative of the concentrations measured in OWW. Such concentrations could allow pharmaceuticals to be used as primary substrate for the biomass. The data obtained in this study permits to calculate kinetic parameters for removal by both types of tested activated sludge (Eq.2) for each pharmaceutical.

$$
\frac{d[\text { Pharmaceutical }]}{d t}=k_{\text {global }} \cdot[\text { Pharmaceutical }]_{\text {initial }}^{n} \quad \text { Eq.2 }
$$


515 kglobal, which is the kinetic constant of total removal measured during the $4 \mathrm{~h}$ test $\left(\mu \mathrm{g}^{1-}\right.$ $\left.516{ }^{n} \cdot L^{n-1} \cdot h^{-1}\right)$, and $n$, which is the order of the reaction, were then determined through 517 linearization (Eq.3) :

$$
\log _{10} \frac{d[\text { Pharmaceutical }]}{d t}=\log _{10} k_{\text {global }}+n \cdot \log _{10}[\text { Pharmaceutical }]_{\text {initial }}
$$

520

521

522

523

524

525

526

527

528

529

530

531

532

Representing this equation allows for the determination of the kinetics constant kglobal (Table 6).

It appears that some degradation kinetics deviate from pseudo-first order, such as that of cyclophosphamide by acclimated sludge. This deviation may be attributed to experimental uncertainties or to inhibition by the pharmaceutical cocktail at the highest concentrations. However, it seems obvious that the order greater than 2 for IF obtained with the Rousset WWTP sludge is due to the WWTP sludge's inability to biotransformate that compound. It is not possible to use a mathematical model for IF. The traditional model of pseudo-first order was not used and the values of the kinetic constants were not compared to literature data because their units depend on the order of the reaction. The biotransformation kinetic constant $\mathrm{k}_{\mathrm{biol}}$ and the associated order of the reaction $\mathrm{n}$ may be determined from concentrations at sorption equilibrium [Pharmaceutical $]_{\text {eq }}$ and final [Pharmaceutical $]_{\mathrm{f}}$ during the total removal test (Eq.4 and Table 6):

$$
\log _{10} \frac{[\text { Pharmaceutical }]_{e q-}[\text { Pharmaceutical }]_{f}}{t_{f}-t_{i}}=\log _{10} k_{\text {biol }}+n \cdot \log _{10}[\text { Pharmaceutical }]_{\text {initial }} \text { Eq.4 }
$$


After integrating equation 2, previously determined kinetic constants and orders of reaction allow for the calculation of the residual concentration of pharmaceuticals according to time (Eq.5):

$$
[\text { Pharmaceutical }](t)=\left[k \cdot t \cdot(n-1)+[\text { Pharmaceutical }]_{\text {initial }}^{(1-n)}\right]^{\frac{1}{1-n}} \quad \text { Eq.5 }
$$

Thus it is possible to represent a removal profile for each pharmaceutical for both types of activated sludge. A profile is proposed with the kglobal constant representing maximum removal of a pharmaceutical, when biotransformation does not limit sorption kinetics and allows for the release of sorption sites onto bacterial flocs. Another profile is represented with the $\mathrm{k}_{\text {global }}$ constant for the first 4 hours, then with only $\mathrm{k}_{\text {biol, }}$ which would be the most unfavorable case, i.e. sorption which does not repeat because of very low biotransformation, which does not allow for the rapid release of sites onto bacterial flocs.

Final concentration in pharmaceuticals was calculated using Eq.6 up to $4 \mathrm{~h}$ then Eq.7 from $4 \mathrm{~h}$ respectively, for the profile, which only takes into account the biotransformation mechanism after $4 \mathrm{~h}$.

From 0 to $4 \mathrm{~h}$ :

$[$ Pharmaceutical $](t)=\left[k_{\text {global }} \cdot t \cdot(n-1)+[\text { Pharmaceutical }]_{\text {initial }}^{(1-n)}\right]^{\frac{1}{1-n}}$ Eq.6

Then with $\mathrm{t}>4 \mathrm{~h}$ :

$$
[\text { Pharmaceutical }](t)=\left[k_{\text {biol }} \cdot(t-4) \cdot(n-1)+[\text { Pharmaceutical }]_{4 h}^{(1-n)}\right]^{\frac{1}{1-n}}
$$


Removal profiles were calculated using the average concentrations of the selected pharmaceuticals measured in the OWW: 26 - 290 - 1664 - $422 \mu \mathrm{g} \cdot \mathrm{L}^{-1}$ for codeine (CD) Cyclophosphamide (CP) - Isofofammide (IF) - Sulfamethoxazole (SM respectively). The temporary absence of a molecule in OWW was not taken into account in the calculation of the average concentration. The evolution of the removal of the 4 pharmaceuticals from the liquid phase was represented for both types of sludge (Figure 7). It should be specified that most of the profiles using kglobal overestimated the removal kinetics of the liquid phase, particularly for the sludge from the Rousset WWTP, as the renewal of sorption sites depends on the biotransformation mechanism. Hence a low biotransformation will limit the sorption kinetics once sorption equilibrium has been attained.

Removal of a pharmaceutical from the liquid phase in a batch reactor is situated between the two curves which were calculated from $\mathrm{k}_{\text {global }}$ and $\mathrm{k}_{\mathrm{biol}}$. So the actual evolution of removal of CD, CP and IF for the Rousset WWTP sludge should follow the curve for removal through biotransformation, as this mechanism limits sorption kinetics. This kinetics is probably close to the kglobal curve for sludge acclimated to OWW, because of the developed biotransformation which is greater than sorption, and close to $\mathrm{k}_{\mathrm{biol}}$ for the sludge from the Rousset municipal WWTP. They are the solid lines in Figure 7.

These profiles show the extent of the capacity for biotransformation developed by activated sludge thanks to on-site treatment of OWW. It seems that SM is the pharmaceutical which presents the smallest number of differences between the two types of sludge. The clearest gain from treatment with activated sludge is for the two antineoplastics (CO and IF), as developed biotransformation enabled us to obtain 
significant removals. Moreover, it is logical to suppose that the profile that best represents removal of antineoplastics for the Rousset WWTP is the profile which only takes into account biotransformation after $4 \mathrm{~h}$, as sorption does not limit the biotransformation mechanism, which proved to be quasi null. Obviously all the removal profiles calculated with the kglobal constant are above the associated profile calculated with the $\mathrm{k}_{\mathrm{biol}}$ constant, except ifosfamide for acclimated sludge, whose two profiles are practically superposed. This superposing clearly shows that sorption is renewed as the biotransformation process of IF takes place. Consequently it is possible to determine the time needed to reach a given reduction. The time needed to obtain a $95 \%$ reduction was determined for both types of sludge (Table 7).

These results clearly demonstrate the gain from the acclimation in an MBR of sludge acclimated to OWW. However, these durations remain far longer than the average HRT of the sMBRe pilot used for the $29 \mathrm{~h}$ acclimation during the experiment. The removals that correspond to this average HRT are presented in Table 8.

This calculated data should be interpreted with caution. Comparing removal kinetics of a batch reactor and of a continuous process may prove delicate, especially as retention of pharmaceuticals by the membrane, as was observed in this study (Hamon, 2013), strongly limits that comparison. This data, calculated from kinetic parameters, would show an excellent removal of IF for acclimated sludge. Still, the performance of the hospital MBR pilot which was used for acclimation proved to be consistently lower. These differences may be attributed to the pharmaceutical cocktail created for the tests in a batch reactor. This cocktail only contained 4 pharmaceuticals, which is far from the great complexity of OWW as to quantity and quality, without even mentioning metabolites. Thus the profile of IF removal by sludge acclimated to OWW may be 
questioned for the reasons mentioned above, because of experimental mistakes, or because of the low experimental concentrations used in IF, compared to OWW concentrations, which would only trigger an inhibitory effect restricted to the biomass.

Removal of CP at average HRT seems more reliable as the $46 \%$ removal calculated from $\mathrm{k}_{\mathrm{biol}}$ is relatively close to reduction in the MBR during acclimation. It should be noted that subtracting the average sorption part of $3.7 \%$ (previously observed for the activated sludge of the hospital sMBRe pilot) from the $46 \%$ removal of CP would give a biotransformation part of $42.3 \%$. This biotransformed fraction of $42.3 \%$ is in the same order of magnitude as the biotransformation measured by Seira (2013) of $39 \pm 5 \%$ in an eMBR pilot treating urban wastewater with a CP dopant. The developed model also seems reliable for SM, as its average removal by the MBR during acclimation (75\%) was between the calculated maximum removal and removal through biotransformation. Lack of data about the sorption of codeine on sludge acclimated to OWW makes it impossible to conclude on the validity of the model for that pharmaceutical.

\section{Conclusion}

Removal of the selected pharmaceutical molecules by activated sludge acclimated to OWW and non-acclimated sludge from the municipal WWTP confirms literature observations on the heterogeneity of the removal of pharmaceuticals. 5-FU was almost systematically removed beyond $90 \%$. This molecule is easily removable, as the performance of WWTP sludge confirmed. It is important to specify that (i) even if removal of 5-FU by sludge acclimated to OWW seems identical to that by WWTP sludge, sludge acclimation was obtained in the presence of other inhibitory compounds contained in the effluents of the oncological ward (pharmaceuticals, surface-active 
agents), which makes the results all the more remarkable, and (ii) using sludge acclimated to OWW allowed for a 34\% increase in the degradation kinetic constant and in the minimum inhibition concentration.

Acclimation of activated sludge to OWW in an MBR brought about the creation of extensive capacity for biotransformation and the acquisition of a very pronounced resistance to the most widely consumed antibiotics in the oncological ward. While sorption is the main, or even the only, removal mechanism by non-acclimated WWTP sludge, treatment by acclimated sludge provides a significant improvement in the removal of the selected pharmaceuticals. Hence $20 \%$ of the amounts of CP, IF and SM can be removed by biotransformation in a mere $4 \mathrm{~h}$. With the exception of codeine for which sorption reaches $30 \%$, sorption of the selected pharmaceuticals onto sludge proved minor, as it was lower than or in the order of $10 \%$ for both types of tested sludge. If removal by sorption is low, adsorbed quantities still remain significant, because of the high concentrations in pharmaceuticals of hospital effluents, and more specifically effluents from a care unit. Thus pollutant transfer from the liquid to the solid phase must be taken into account when determining the suitable process for the treatment of sludge.

These results are positive, as they show that the observed removal of pharmaceutical molecules by an acclimated biomass can mostly be attributed to developed biotransformation, in comparison with the sorption phenomenon. The acclimated activated sludge showed a great capacity for adaptation to the pharmaceuticals contained in the OWW. That observation is supported by the conservation of the purifying capacities of the biomass in the presence of a pharmaceutical cocktail, the acquisition of a pronounced resistance to antibiotics and, most of all, by the creation of 
29

\section{ACCEPTED MANUSCRIPT}

656 biotransformation capacities on the selected pharmaceuticals. A systematic

657 improvement of the performance of the acclimated activated sludge, compared to that of

658 activated WWTP sludge, was obtained in spite of the presence of numerous compounds

659 (pharmaceuticals, metabolites, and cleaning products) in the OWW. These compounds

660 sometimes inhibited the development of the biomass and its purifying performance on

661 the COD, ammonium and nitrates during acclimation. Furthermore, it has to be noted

662 that the development of a pronounced resistance to antibiotics must be seriously

663 studied with regard to human health and the environment in order to validate the

664 biological treatment at the source of highly concentrated antibiotics effluent.

665

666 Acknowledgements

667 The authors acknowledge the Ianesco laboratory (Institut d'Analyses et d'Essais en 668 Chimie de l'Ouest, Poitiers, France) for their help.

669 
30

\section{ACCEPTED MANUSCRIPT}

\section{List of symbols}

$\begin{array}{ll}\text { 5-FU } & \text { Fluorouracile } \\ \text { OWW } & \text { oncological ward wastewater } \\ \text { WWTP } & \text { wastewater treatment plant } \\ \text { eMBR } & \text { external membrane bioreactor } \\ & \text { external submerged membrane } \\ \text { SMBRe } & \text { bioreactor } \\ \text { TSS } & \text { Total Suspended Solids }\left(\mathrm{g} \cdot \mathrm{L}^{-1)}\right. \\ \text { COD } & \text { chemical oxygen demand }\left(\mathrm{mgO}_{2} \cdot \mathrm{L}^{-1}\right) \\ \mathrm{CP} & \text { cyclophosphamide } \\ \text { IF } & \text { ifosfamide } \\ \text { SM } & \text { sulfamethoxazole } \\ \text { CD } & \text { codeine } \\ \text { CF } & \text { concentration factor } \\ \text { SRT } & \text { sludge retention time } \\ \text { HRT } & \text { hydraulic retention time }(\mathrm{h})\end{array}$

\begin{tabular}{|c|c|c|}
\hline$k_{\text {biol }}$ & Biotransformation kinetic constant & L.gTSS ${ }^{-1} \cdot d^{-1}$ \\
\hline$K_{D}$ & Solid-water distribution coefficient & L.kgTSS $^{-1}$ \\
\hline kglobal & Maximum removal constant & $\mu g^{1-n} \cdot L^{n-1} \cdot d^{-1}$ \\
\hline $\begin{array}{l}{[5-} \\
\mathrm{FU}]_{\max }\end{array}$ & 5-FU maximum concentration detected in OWW & $\mu g . L^{-1}$ \\
\hline $\mathrm{n}_{\text {med }}$ & $\begin{array}{l}\text { Yearly amount of pharmaceutical molecule consumed in the } \\
\text { oncological ward }\end{array}$ & mg.year ${ }^{-1}$ \\
\hline $\mathrm{n}_{5-\mathrm{FU}}$ & Yearly amount of 5-FU consumed in the oncological ward & mg.year ${ }^{-1}$ \\
\hline $1-\tau_{\text {med }}$ & Rate of unmetabolized pharmaceutical & - \\
\hline $1-\tau_{5-F U}$ & Rate of unmetabolized 5-FU & - \\
\hline
\end{tabular}


675

676

677

678

679

680

681

682

683

684

685

686

687

688

689

690

691

692

693

694

\section{Reference}

Abegglen C., Joss A., McArdell C., Fink G., Schlüsener M., Ternes T., Siegrist H., 2009. The fate of selected micropollutants in a single-house MBR. Water Research 43, 2036-2046.

Barrios-Martinez, A., E. Barbot, B. Marrot, P. Moulin and N. Roche, Degradation of phenol-containing effluents by MBR. J. Membrane Sci., 288 (2006) 288-296.

Buerge I., Buser H., Poiger T., Müller M., 2006. 1st Network Conference on Persistent Organic Pollutants: Human Exposure and Impacts, University of Birmingham, March 29-30, 2006.

Delgado L., 2009. Bioréacteur à membrane externe pour le traitement d'effluents contenant des médicaments anticancéreux : élimination et influence du cyclophosphamide et de ses principaux métabolites sur le procédé. Thèse de doctorat, INP Toulouse.

Göbel A., Thomsen A., McArdell C., Joss A., Giger W., 2005. Occurrence and Sorption Behavior of Sulfonamides, Macrolides, and Trimethoprim in Activated Sludge Treatment. Environ. Sci. Technol. 39, 3981-3989.

Hann, S., $\mathbb{E}$ Zs. Stefanka $\mathbb{A}$ K. Lenz $\mathbb{E}$ G. Stingeder. Novel separation method for highly sensitive speciation of cancerostatic platinum compounds by HPLC-ICP-MS. Anal Bioanal Chem (2005) 381: 405-412.

Hamon, P., 2013. Traitement des effluents d'un service d'oncologie par bioréacteur à membranes : faisabilité d'acclimatation et gain apporté sur l'élimination de molécules médicamenteuses, Thèse d'Aix Marseille Université 
695

696

697

698

699

700

701

702

703

704

705

706

707

708

709

710

711

712

713

714

715

Hamon P., Villain M., Marrot B., 2014. Determination of sorption properties of micropollutants: What is the most suitable activated sludge inhibition technique to preserve the biomass structure? Chemical Engineering Journal 242, 260-268.

Henriques I., Holbrook R., Kelly R., Love N., 2005. The impact of floc size on respiration inhibition by soluble toxicants-a comparative investigation. Water Research 39, 2559-2568.

Henriques I., Love N., 2007. The role of extracellular polymeric substances in the toxicity response of activated sludge bacteria to chemical toxins. Water Research 41, 4177-4185.

Hörsing M., Ledin A., Grabic R., Fick J., Tysklind M., Jansen J., Andersen H., 2011. Determination of sorption of seventy-five pharmaceuticals in sewage sludge. Water Research $45,4470-4482$.

Joss A., Keller E., Alder A., Göbel A., McArdell C., Ternes T., Siegrist H., 2005. Removal of pharmaceuticals and fragrances in biological wastewater treatment. Water Research 39, 3139-3152.

Joss A., Zabczynski S., Göbel A., Hoffmann B., Löffler D., McArdell C., Ternes T., Thomsen A., Siegrist H., 2006. Biological degradation of pharmaceuticals in municipal wastewater treatment: Proposing a classification scheme. Water Research 40, 1686-1696.

Kiffmeryer T., Götze H., Jursch M., Lüders U., 1998. Trace enrichment, chromatographic separation and biodegradation of cytostatic compounds in surface water. Fresenius J Anal Chem 361, 185-191

Kosjek T., Perko S., Zigon D., Heath E., 2013. Fluorouracil in the environment: Analysis, occurrence, degradation and transformation. Journal of Chromatography A 1290, 66-72.

Kümmerer K., Steger-Hartmann T., Meyer M., 1997. Biodegradability of the anti-tumour agent ifosfamide and its occurrence in hospital effluents and communal sewage. Water Research 31 (11), 2705-2710. 

cytarabine, and gemcitabine: impact of the chemical structure and synergistic toxicity with hospital effluent. Acta Hydrochim. Hydrobiol. 25 (4), 166-172.

Kummerer K., Helmers E., 1997. Hospital effluents as a source of platinum for the environment. Science of Total Environment 193, 179-184. present knowledge and future challenges. Journal of Environmental Management 90 (8), 2354 2366.

Mahnik S., Lenz K., Weissenbacher N., Mader R., Fuerhacker M., 2007. Fate of 5-fluorouracil, doxorubicin, epirubicin, and daunorubicin in hospital wastewater and their elimination by activated sludge and treatment in a membrane-bio-reactor system. Chemosphere 66, 30-37.

Okuda T., Yamashita N., Tanaka H., Matsukawa H., Tanabe K., 2009. Development of extraction method of pharmaceuticals and their occurrences found in Japanese wastewater treatment plants. Environment International 35, 815-820.

Radjenovic J., Petrovic M., Barcelo D., 2009. Fate and distribution of pharmaceuticals in wastewater and sewage sludge of the conventional activated sludge (CAS) and advanced membrane bioreactor (MBR) treatment. Water Research 43, 831-841. Interscience. 
737 Seira J., 2013. Rôle de la sorption et de la biodégradation dans l'élimination de micropolluants par

738 des procédés d'épuration biologique: application aux molécules anticancéreuses traitées par

739 bioréacteur à membrane. Thèse de doctorat, Université de Toulouse.

Sipma J., Osuna B., Collado N., Monclus H., Ferrero G., Comas J., Rodriguez-Roda I., 2010. Comparison of removal of pharmaceuticals in MBR and activated sludge systems. Desalination 250 (2), 653-659.

Stevens-Garmon J., Drewes J., Khan S., McDonald J., Dickenson E., 2011. Sorption of emerging trace organic compounds onto wastewater sludge solids. Water Research 45, 3417-3426.

Suarez S., Lema J., Omil F., 2010. Removal of pharmaceuticals and personal care products (PPCPs) under nitrifying and denitrifying conditions. Water Research 44, 3214-3224.

Tadkaew N., Sivakumar M., Khan S., McDonald J., Nghiem L., 2010. Effect of mixed liquor pH on the removal of trace organic contaminants in a membrane bioreactor. Bioresource Technology 101, 1494-1500. the solid-water distribution coefficient (Kd) for pharmaceuticals and musk fragrances in sewage sludge. Water Research 38, 4075-4084. estrogens in membrane separation bioreactors. Desalination 178, 107-113. 
757 Wick A., Fink G., Joss A., Siegrist H., Ternes T., 2009. Fate of beta blockers and psycho-active drugs in

758 conventional wastewater treatment. Water Research 43, 1060-1074.

759 Yang S., Lin C., Lin A., Hong P., 2011. Sorption and biodegradation of sulfonamide antibiotics by 760 activated sludge: Experimental assessment using batch data obtained under aerobic conditions. 761 Water Research 45, 3389-3397.

762 Yu J., Bouwer E, Coelhan M., 2006. Occurrence and biodegradability studies of selected 763 pharmaceuticals and personal care products in sewage effluent. Agricultural Water Management 86, $764 \quad 72-80$

765 Zaviska F., Drogui P., Grasmick A., Azais A., Héran M., 2013. Nanofiltration membrane bioreactor for 766 removing pharmaceutical compounds. Journal of Membrane Science 429, 121-129. 
772

773

774

775

776

777

778

779

780

781

782

783

784

785

786

787

788

789

790

791

792

\section{List of Tables and Figures}

Figure 1. Specific removal velocity of 5-FU in eMBR treating OWW.

Figure 2. 5-FU removal in batch reactor for activated sludge from municipal WWTP and activated sludge from the eMBR treating OWW.

Figure 3. Evolution of $k_{\text {biol }}$ for activated sludge from municipal WWTP and eMBR treating OWW.

Figure 4. COD specific removal velocity in presence of pharmaceuticals for activated sludge from municipal WWTP and the eMBR treating OWW.

Figure 5. Removal of the selected pharmaceuticals due to sorption (a) and values of $K_{D}$ for the selected pharmaceuticals (b) for both activated sludge from municipal WWTP and the sMBRe treating OWW.

Figure 6. 4hours removal of the selected pharmaceuticals for both activated sludge from municipal WWTP and the sMBRe treating OWW.

Figure 7. Removal evolution of the 4 selected pharmaceuticals by both activated sludge.

Table 1: State and performance of activated sludge at the sampling date

Table 2: Concentrations of the antineoplastic and antibiotics cocktail

Table 3: Quantity of sorbed pharmaceutical onto activated sludge.

Table 4. $K_{D}$ values of selected pharmaceuticals reported in previous studies. 
793 Table 5.4 hours removal of the selected pharmaceuticals by both activated sludge.

794 Table 6. $\mathrm{k}$ and $\mathrm{n}$ values for the total and biotransformation removal by both activated sludge.

795 Table 7. Required duration to achieve $95 \%$ removal of the selected pharmaceuticals for both 796 activated sludge.

797 Table 8. Removals of the selected pharmaceuticals for both activated sludge at the average 798 HRT of $29 \mathrm{~h}$ of the sMBRe pilot treating OWW.

799

800 


\section{List of Tables and Figures}

Figure 1. Specific removal velocity of 5-FU in eMBR treating OWW.

Figure 2. 5-FU removal in batch reactor for activated sludge from municipal WWTP and activated sludge from the eMBR treating OWW.

Figure 3. Evolution of $k_{\text {biol }}$ for activated sludge from municipal WWTP and eMBR treating OWW.

Figure 4. COD specific removal velocity in presence of pharmaceuticals for activated sludge from municipal WWTP and the eMBR treating OWW.

Figure 5. Removal of the selected pharmaceuticals due to sorption (a) and values of $K_{D}$ for the selected pharmaceuticals (b) for both activated sludge from municipal WWTP and the sMBRe treating OWW.

Figure 6. 4hours removal of the selected pharmaceuticals for both activated sludge from municipal WWTP and the SMBRe treating OWW.

Figure 7. Removal evolution of the 4 selected pharmaceuticals by both activated sludge.

Table 1: State and performance of activated sludge at the sampling date

Table 2: Concentrations of the antineoplastic and antibiotics cocktail

Table 3: Quantity of sorbed pharmaceutical onto activated sludge.

Table $4 . K_{D}$ values of selected pharmaceuticals reported in previous studies.

Table 5.4 hours removal of the selected pharmaceuticals by both activated sludge.

Table $6 . \mathrm{k}$ and $\mathrm{n}$ values for the total and biotransformation removal by both activated sludge.

Table 7. Required duration to achieve $95 \%$ removal of the selected pharmaceuticals for both activated sludge.

Table 8. Removals of the selected pharmaceuticals for both activated sludge at the average HRT of $29 \mathrm{~h}$ of the sMBRe pilot treating OWW. 
2

30

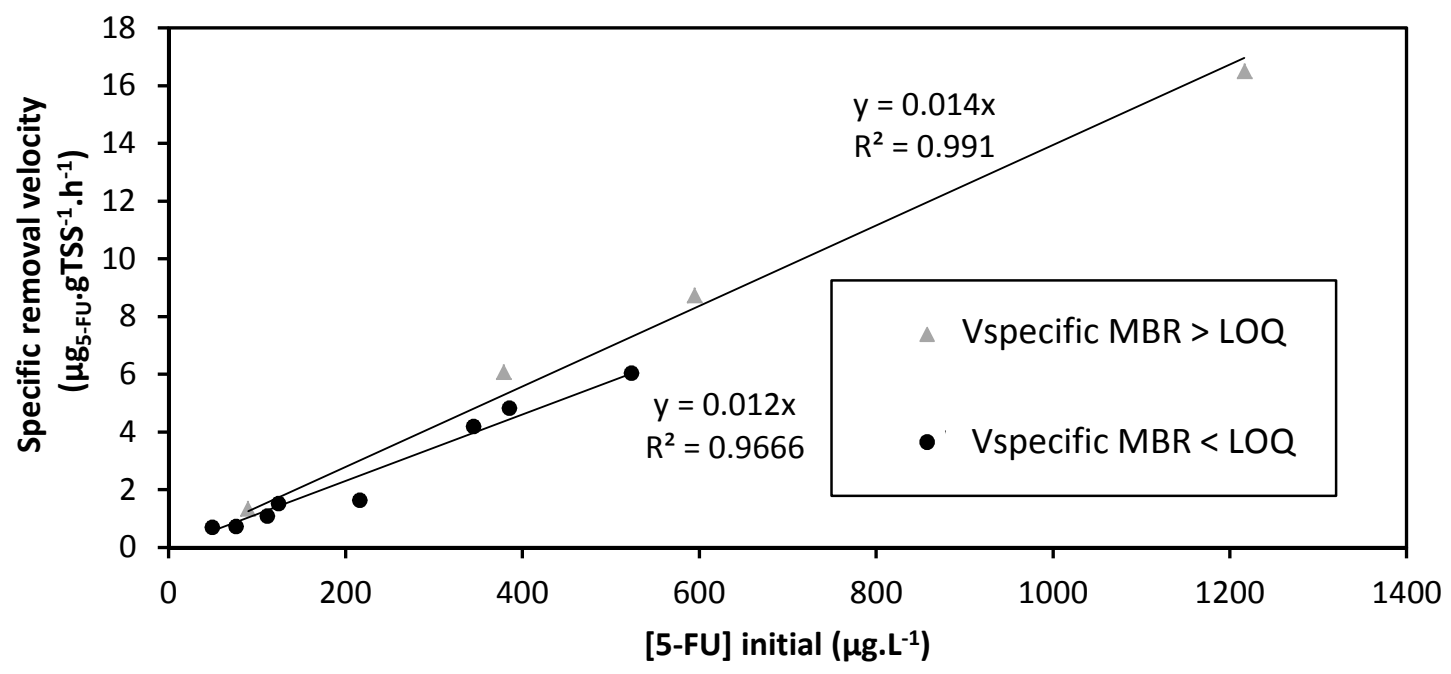

31

Figure 1. Specific removal velocity of 5-FU in eMBR treating OWW. 
3

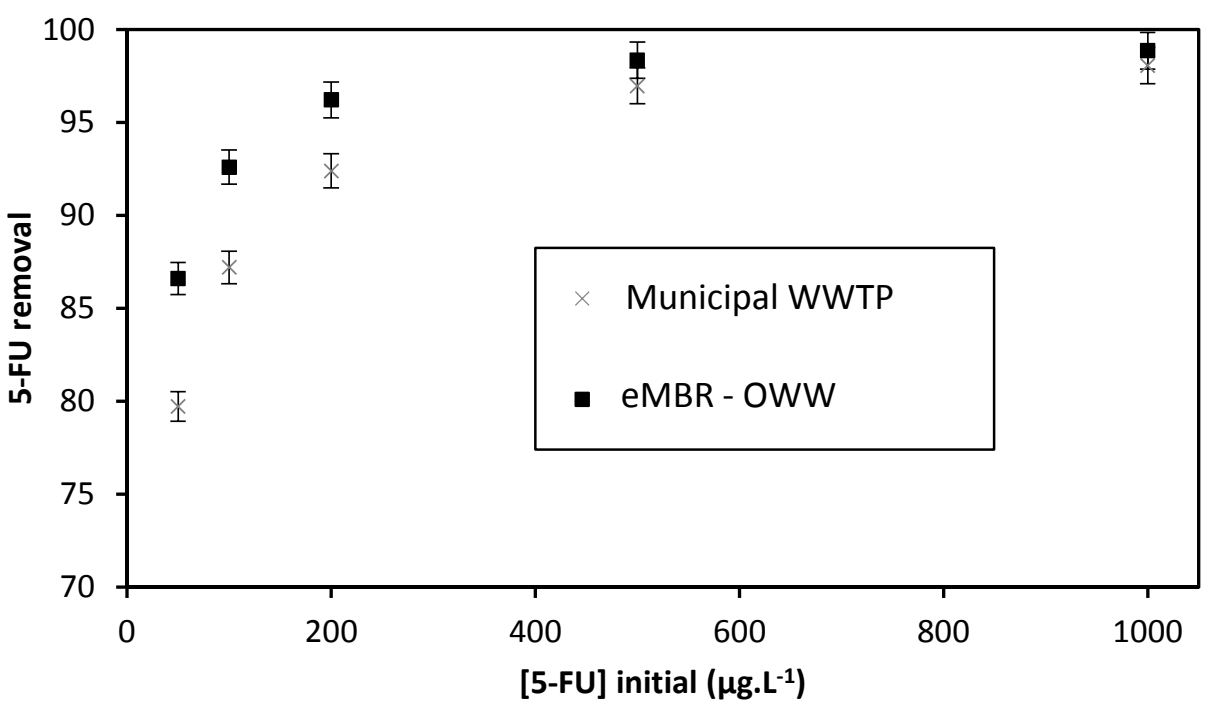

Figure 2. 5-FU removal in batch reactor for activated sludge from municipal WWTP and activated sludge from the eMBR treating OWW. 


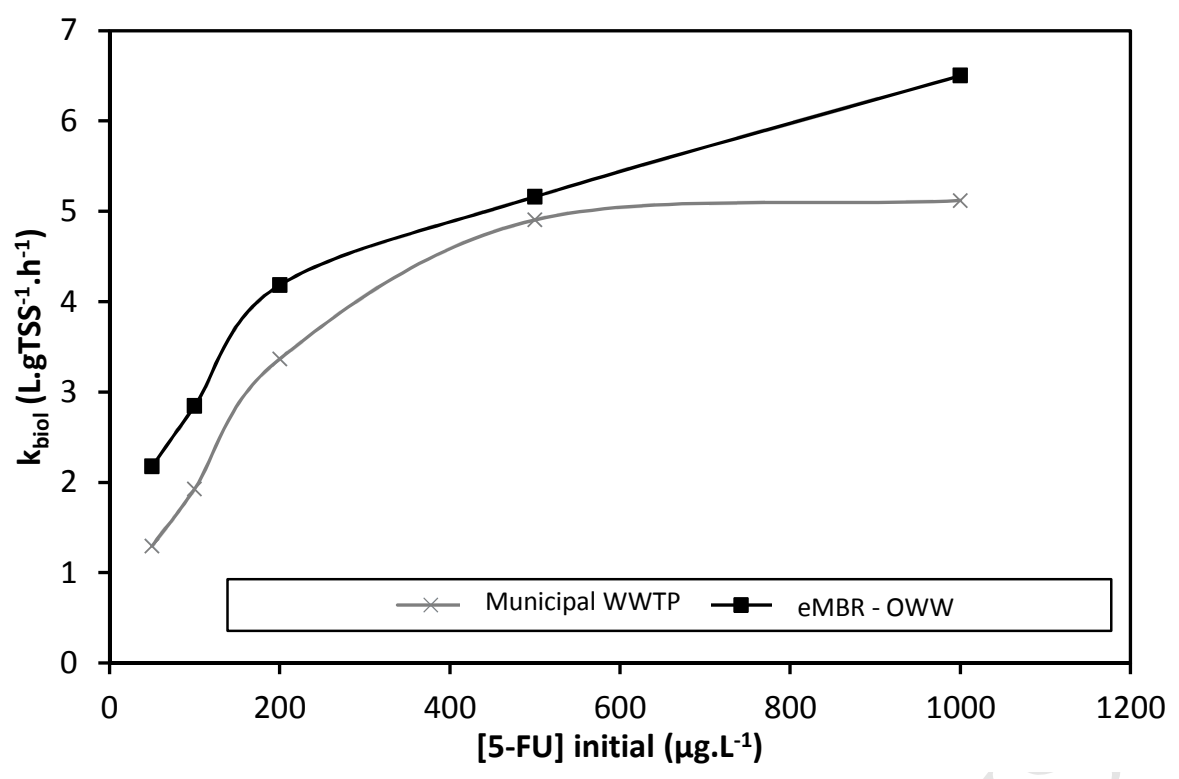

40

Figure 3. Evolution of $k_{b i o l}$ for activated sludge from municipal WWTP and eMBR treating OWW. 


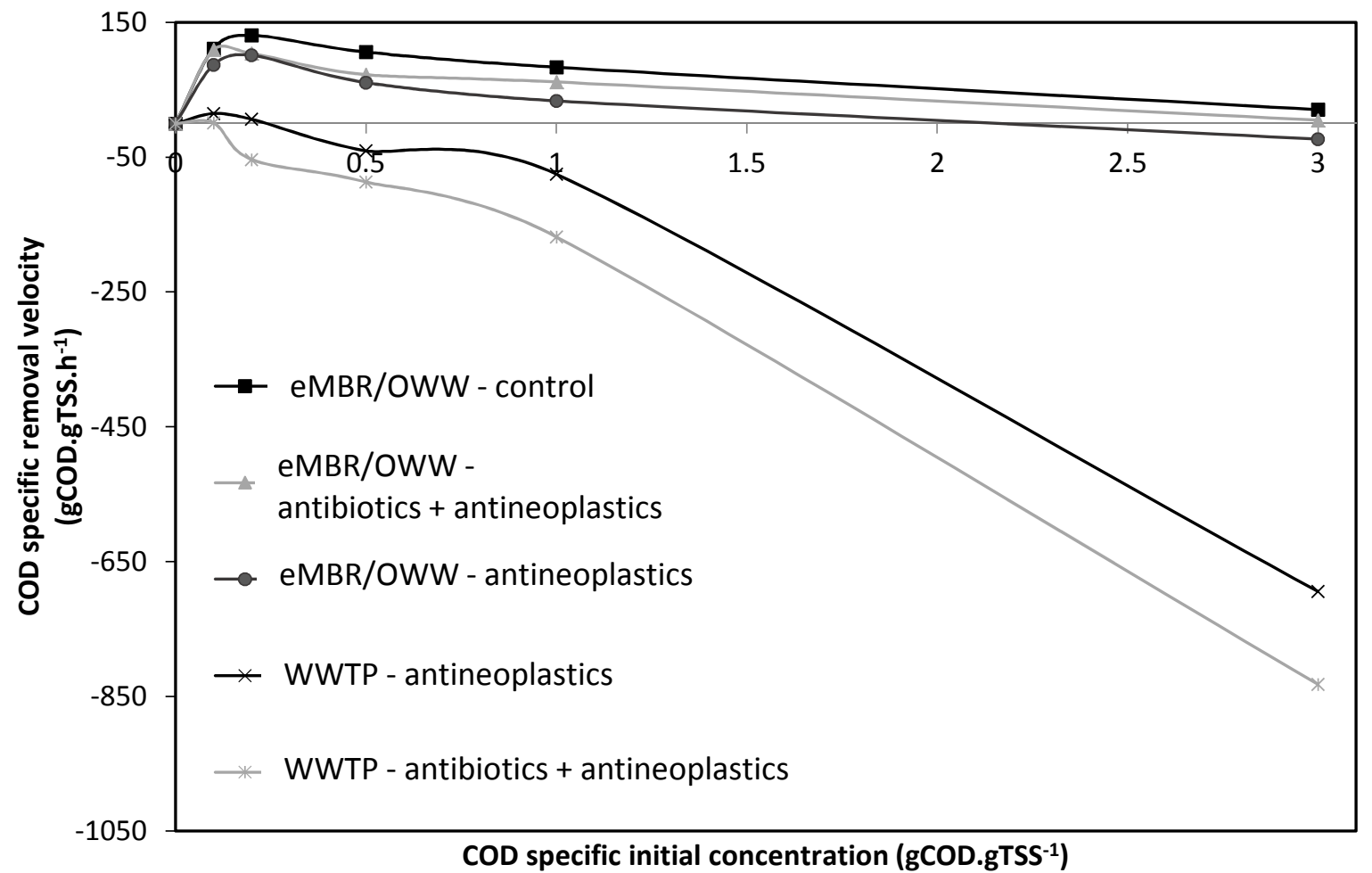

Figure 4. COD specific removal velocity in presence of pharmaceuticals for activated sludge from municipal WWTP and the eMBR treating OWW. 

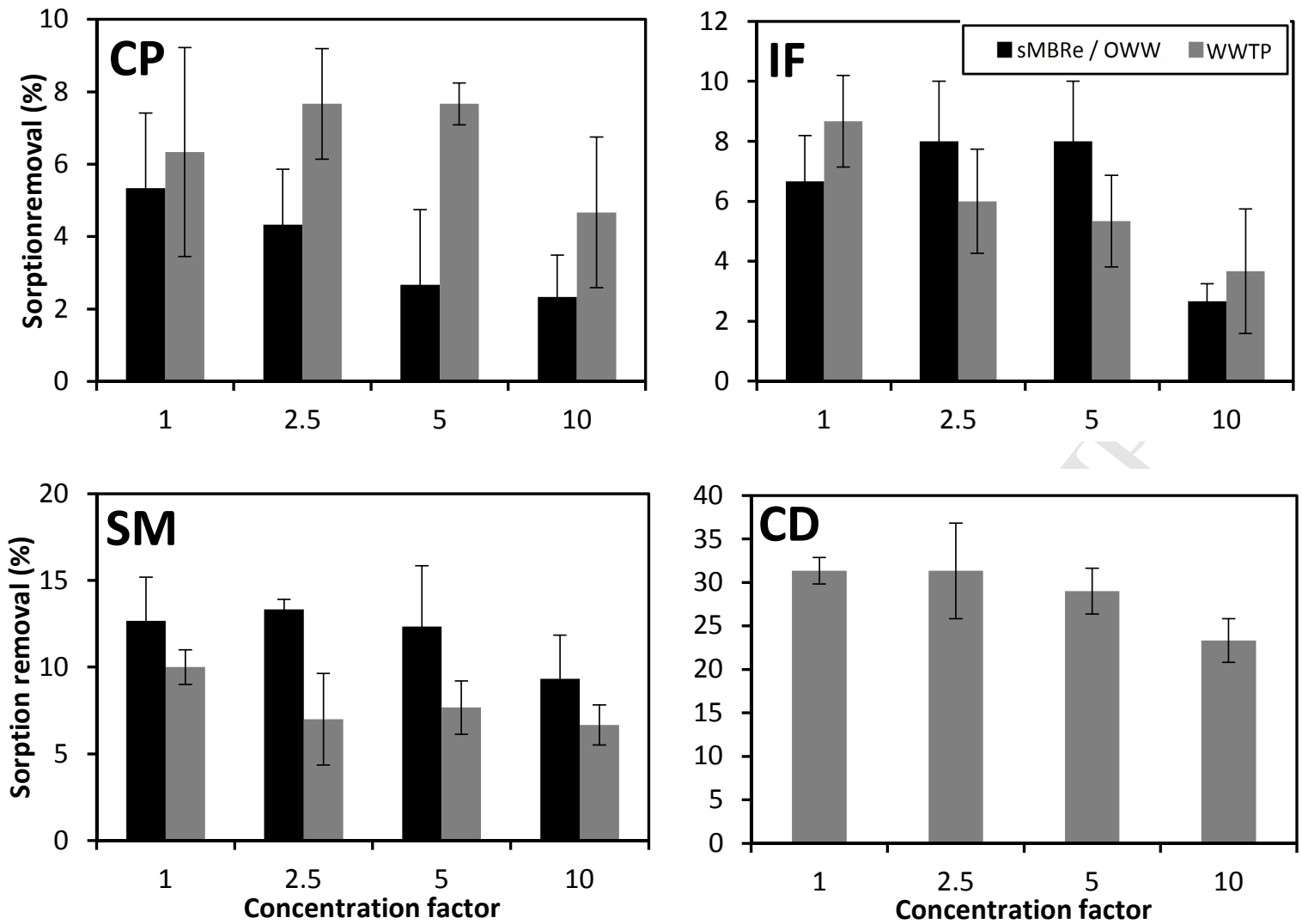

47 48

49
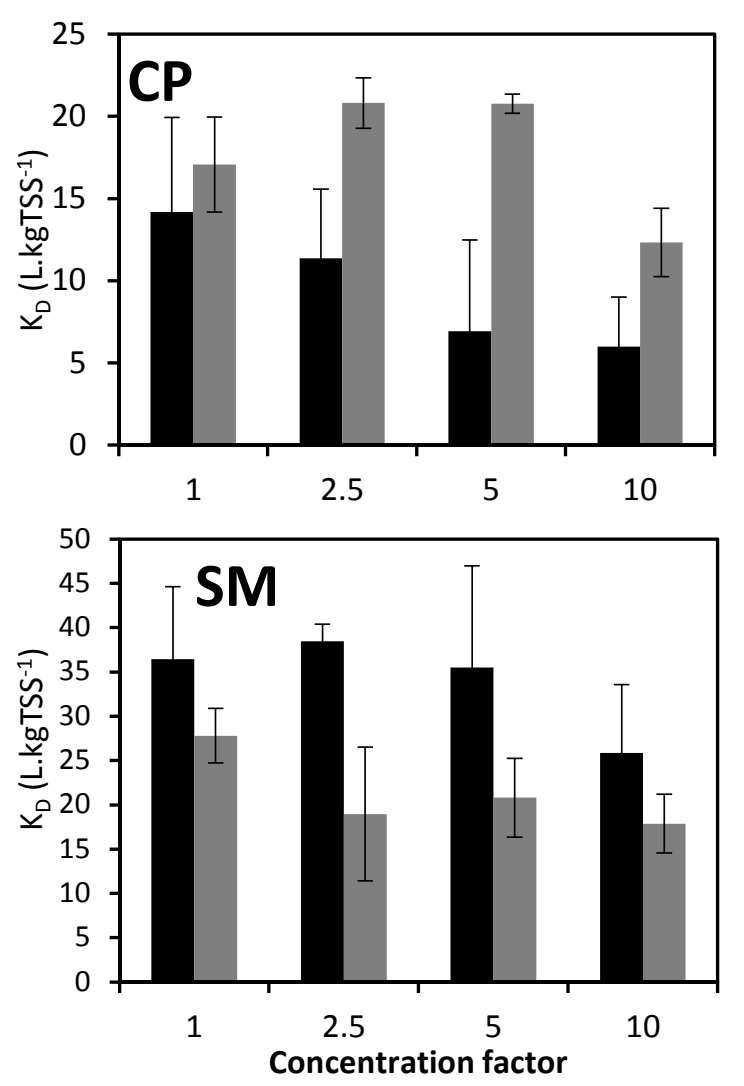

(a)
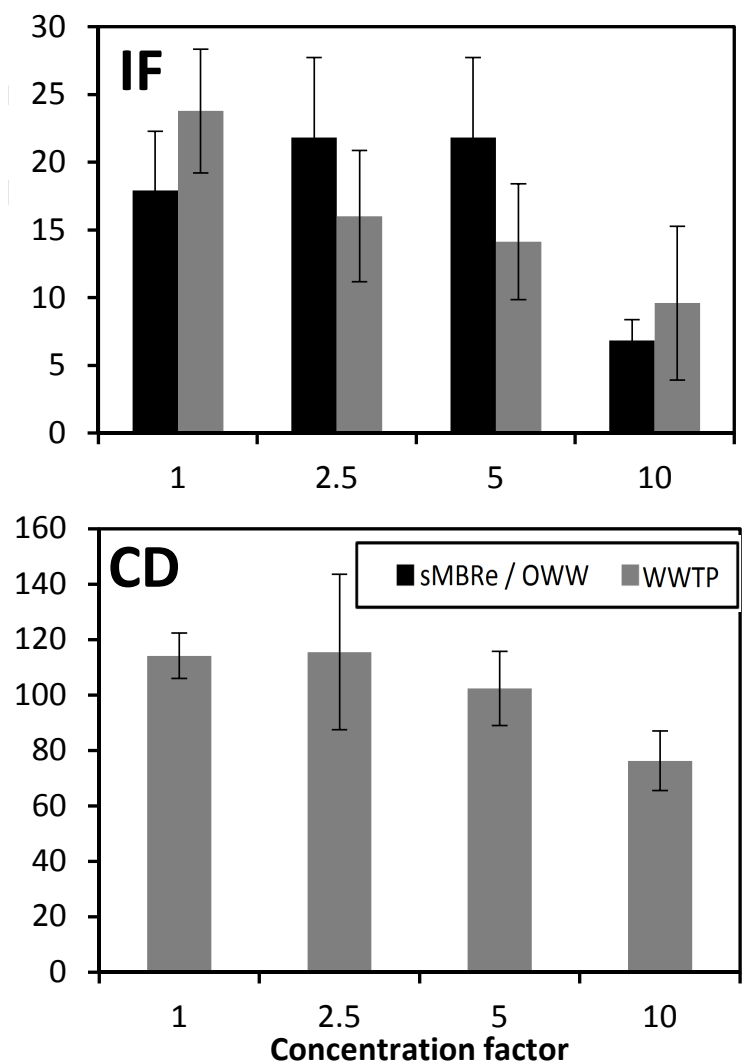

(b) 
Figure 5. Removal of the selected pharmaceuticals due to sorption (a) and values of $K_{D}$ for the selected pharmaceuticals (b) for both activated sludge from municipal WWTP and the SMBRe treating OWW. 

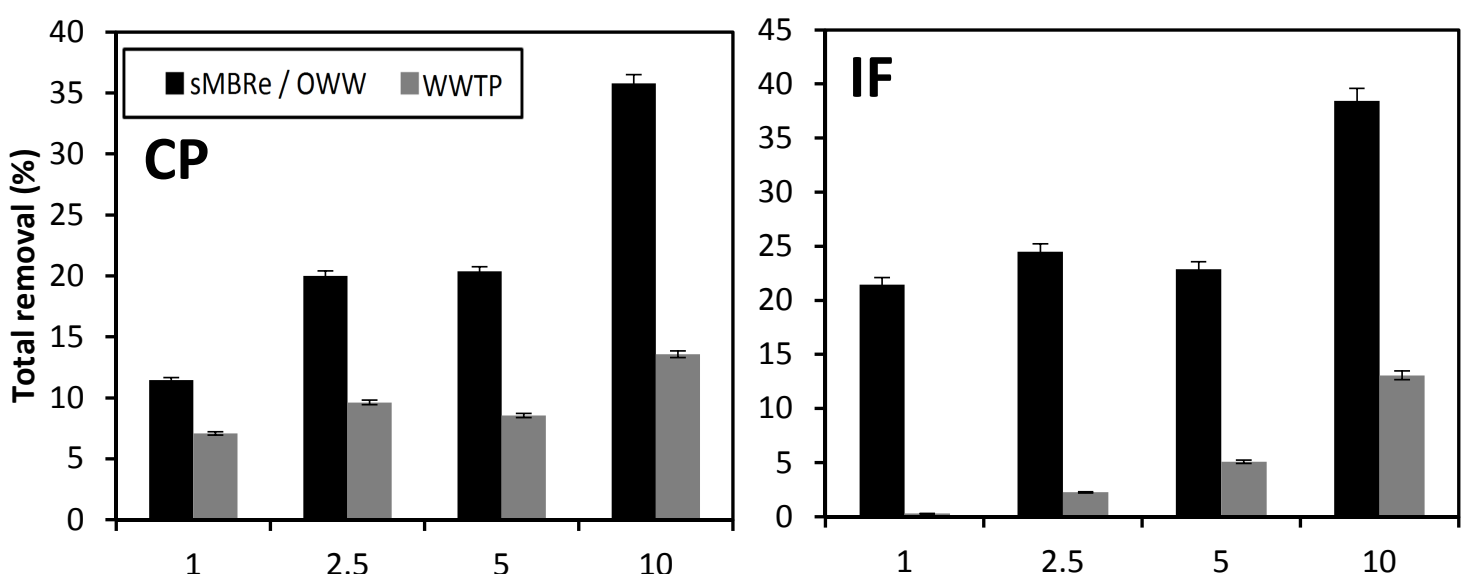

55
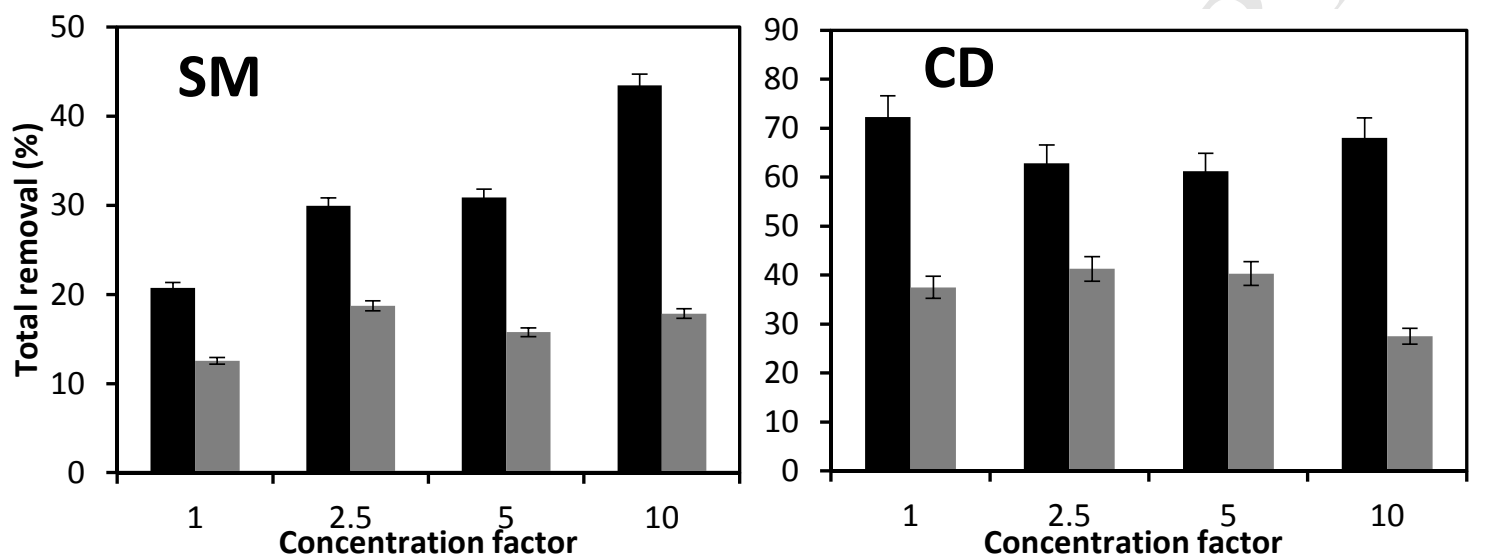

Figure 6. 4hours removal of the selected pharmaceuticals for both activated sludge from municipal WWTP and the SMBRe treating OWW. 
60
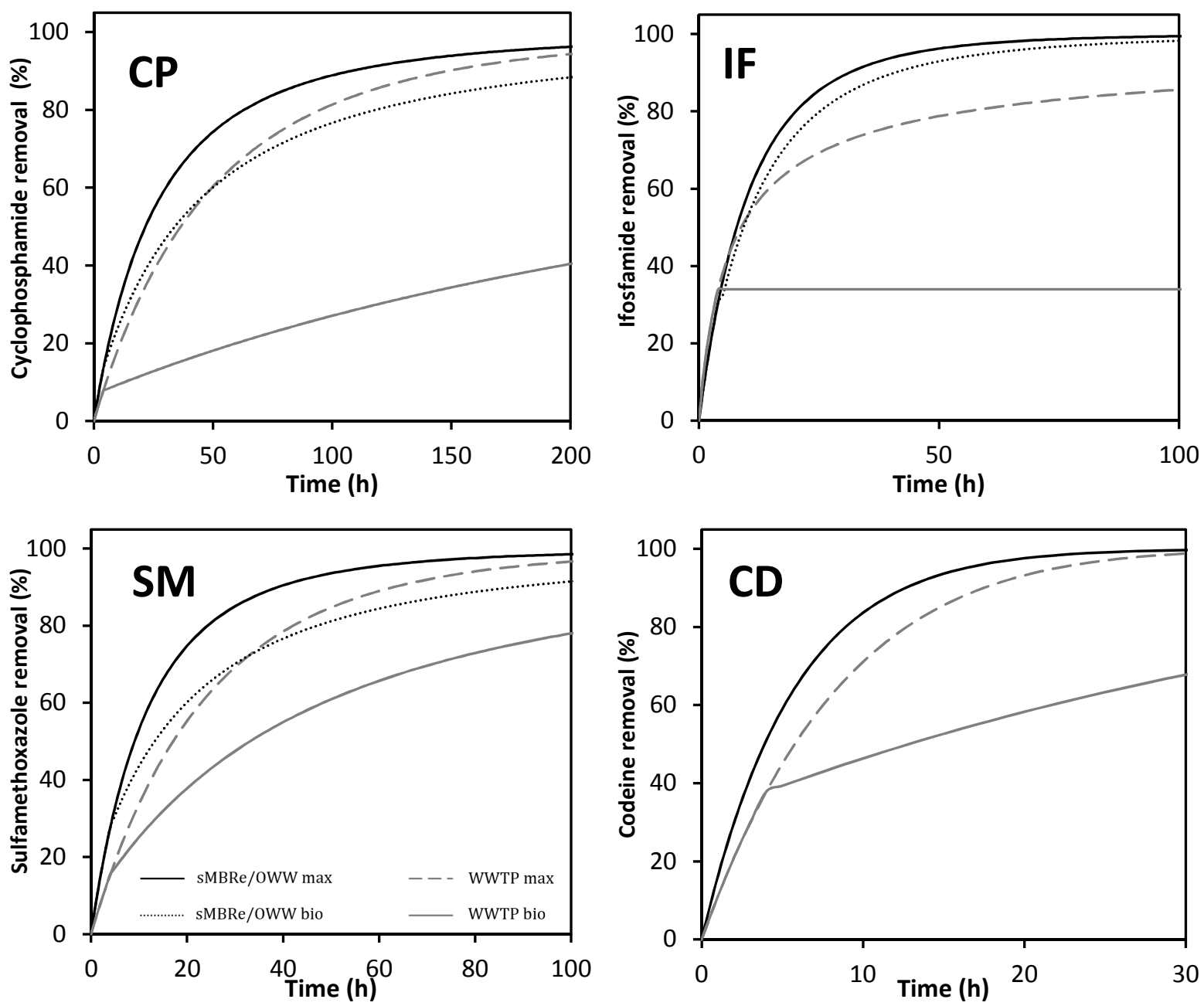

Figure 7. Removal evolution of the 4 selected pharmaceuticals by both activated sludge. 
Table 1: State and performance of activated sludge at the sampling date

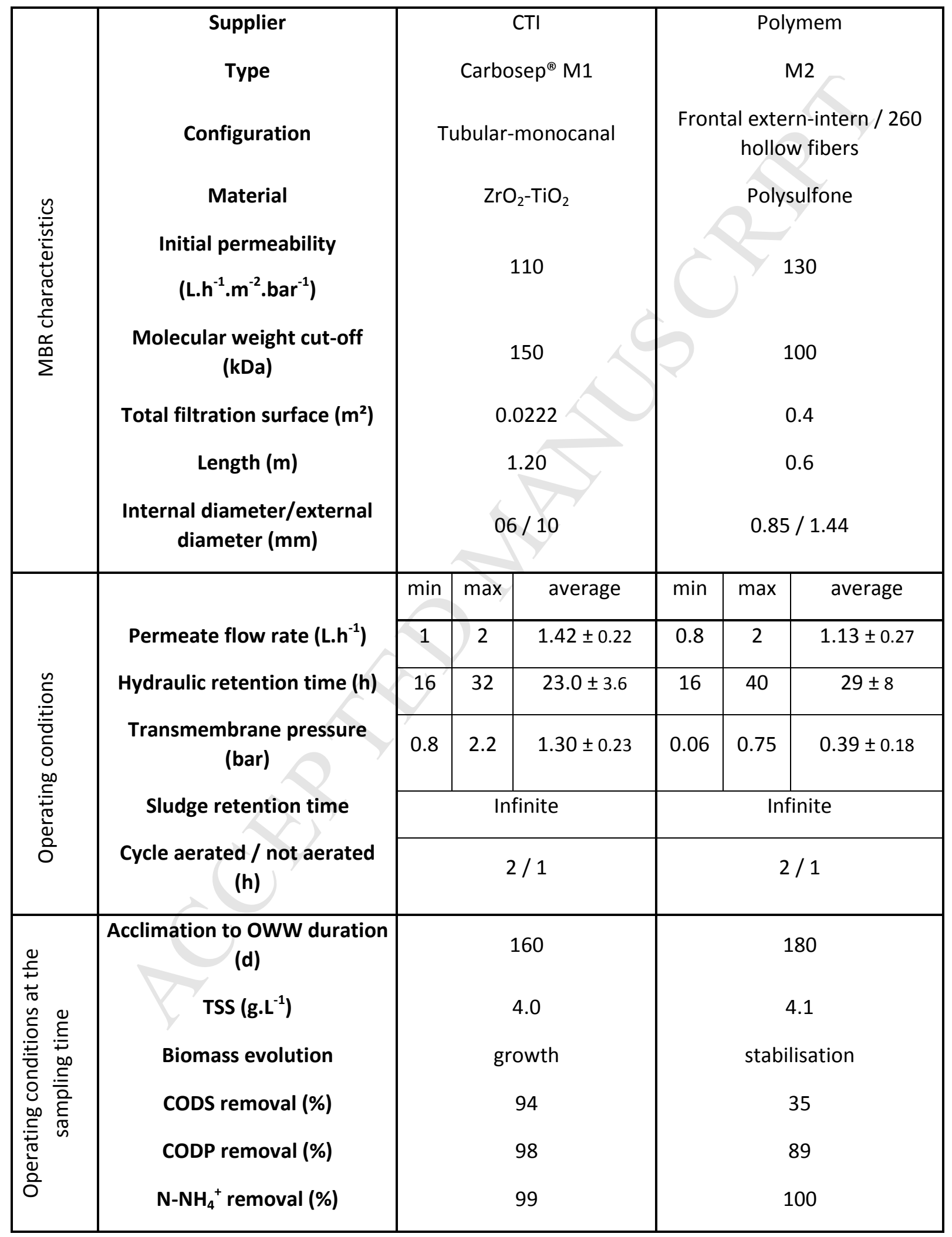


12

Table 2: Concentrations of the antineoplastic and antibiotic cocktail

\begin{tabular}{cc}
\hline Antineoplastic & $\begin{array}{c}\text { Concentration } \\
\left(\mu \mathrm{\mu g} . \mathrm{L}^{-1}\right)\end{array}$ \\
\hline 5-FU & 1300 \\
Carboplatin & 600 \\
Etoposide & 600 \\
Doxorubicin & 400 \\
Cisplatin & 400 \\
Cytarabine & 200 \\
Methotrexate & 150 \\
Gemcitabine & 150 \\
Total & $\mathbf{3 8 0 0}$ \\
\hline Antibiotic & Concentration \\
& $\left(\boldsymbol{\mu g} . \mathrm{L}^{-1}\right)$ \\
\hline Ticarcillin & 1000 \\
Amoxicillin & 1000 \\
Ciprofloxacin & 1000 \\
Ceftriaxone & 1000 \\
Total & $\mathbf{4 0 0 0}$ \\
\hline
\end{tabular}




\section{ACCEPTED MANUSCRIPT}

72

73

Table 3: Quantity of sorbed pharmaceutical onto activated sludge.

\begin{tabular}{ccccc} 
Molecule & $\begin{array}{c}\text { OWW } \\
\left(\mu \mathrm{g} . \mathrm{L}^{-1}\right)\end{array}$ & $\mathrm{CF}$ & $\begin{array}{c}\text { Corresponding } \\
(\%)\end{array}$ & $\begin{array}{c}\text { Specific quantity of sorbed } \\
\text { pharmaceutical }\left(\mu \mathrm{g} . \mathrm{gTSS}^{-1}\right)\end{array}$ \\
\hline CD & 26 & 1 & $31.3($ WWTP) & 2 \\
CP & 290 & 2.5 & 4.3 & 3 \\
IF & 1664 & 10 & 2.7 & 11 \\
SM & 422 & 5 & 12.3 & 13 \\
\hline
\end{tabular}

74

75 
Table 4. $K_{D}$ values of selected pharmaceuticals reported in previous studies.

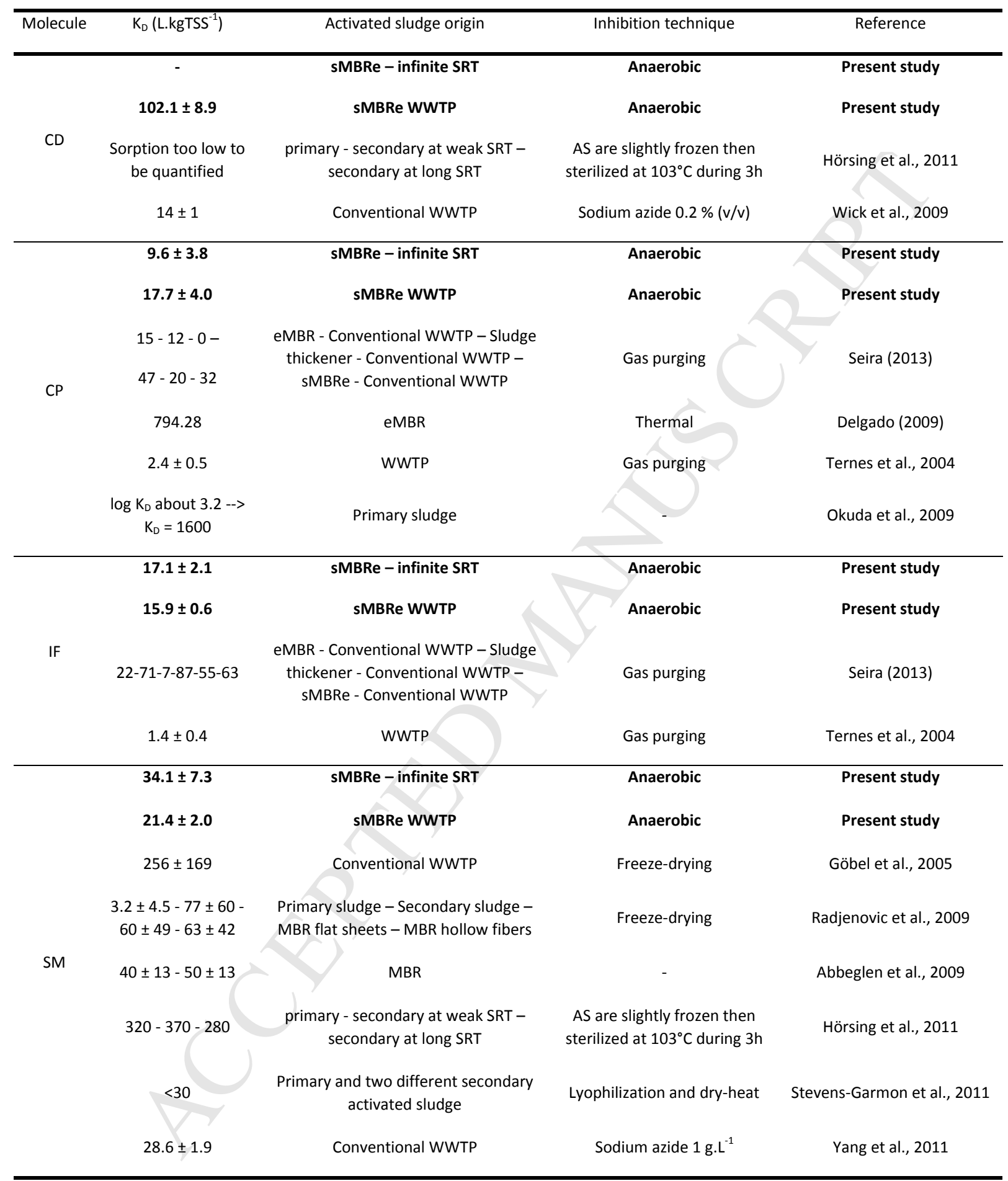


15

\section{ACCEPTED MANUSCRIPT}

80

Table 5. 4 hours removal of the selected pharmaceuticals by both activated sludge.

\begin{tabular}{|c|c|c|c|c|c|c|c|c|}
\hline \multirow[b]{2}{*}{ Molecule } & \multicolumn{4}{|c|}{ sMBRe - acclimated to OWW } & \multicolumn{4}{|c|}{ sMBRe municipal WWTP } \\
\hline & Total (\%) & $\begin{array}{c}\text { Biotrans } \\
\text { formation (\%) }\end{array}$ & $\begin{array}{l}\text { Sorption } \\
(\%)\end{array}$ & $\frac{\text { Biotransformation }}{\text { Sorption }}$ & Total (\%) & $\begin{array}{c}\text { Biotrans } \\
\text { formation (\%) }\end{array}$ & $\begin{array}{l}\text { Sorption } \\
(\%)\end{array}$ & $\frac{\text { Biotransformation }}{\text { Sorption }}$ \\
\hline$C D$ & $66.1 \pm 5.1$ & - & - & - & $36.6 \pm 6.3$ & 7.9 & $28.7 \pm 3.8$ & 0.3 \\
\hline $\mathrm{CP}$ & $\begin{array}{c}21.9 \pm \\
10.1\end{array}$ & 18.2 & $3.7 \pm 1.4$ & 4.9 & $9.7 \pm 2.8$ & 3.1 & $6.6 \pm 1.4$ & 0.5 \\
\hline IF & $26.8 \pm 7.9$ & 20.5 & $6.3 \pm 2.5$ & 3.2 & $5.2 \pm 5.6$ & -0.7 & $5.9 \pm 2.1$ & Solely sorption \\
\hline SM & $31.3 \pm 9.4$ & 19.4 & $11.9 \pm 1.8$ & 1.6 & $16.2 \pm 2.7$ & 8.4 & $7.8 \pm 1.5$ & 1.1 \\
\hline
\end{tabular}

81

*Values presented relate the average removals calculated from the 4 concentration factors.

82 
Table 6. $\mathrm{k}$ and $\mathrm{n}$ values for the total and biotransformation removal by both activated sludge.

\begin{tabular}{|c|c|c|c|c|}
\hline \multicolumn{3}{|c|}{ Total removal } & \multicolumn{2}{|c|}{$\mathrm{TSS}=4 \mathrm{~g} \cdot \mathrm{L}^{-1}-\mathrm{t}=4 \mathrm{~h}$} \\
\hline & \multicolumn{2}{|c|}{ sMBRe/OWW } & \multicolumn{2}{|c|}{ sMBRe/municipal WWTP } \\
\hline Molecule & $\begin{array}{c}k_{\text {global }} \\
\left(\mu g^{1-n} \cdot L^{n-1} \cdot d^{-1}\right)\end{array}$ & $\mathrm{n}$ & $\begin{array}{c}k_{\text {global }} \\
\left(\mu g^{1-n} \cdot L^{n-1} \cdot d^{-1}\right)\end{array}$ & $\mathrm{n}$ \\
\hline Codeine (CD) & 4.680 & 1 & 4.056 & 0.9 \\
\hline Cyclophosphan & 0.072 & 1.5 & 0.120 & 1.2 \\
\hline Ifosfamide (IF) & 0.456 & 1.2 & $1.30 \mathrm{E}-05$ & 2.7 \\
\hline Sulfamethoxazı & 0.336 & 1.3 & 0.480 & 1.1 \\
\hline \multicolumn{5}{|c|}{ Biotransformation removal } \\
\hline & \multicolumn{2}{|c|}{ sMBRe/OWW } & \multicolumn{2}{|c|}{ sMBRe/municipal WWTP } \\
\hline Molecule & $\begin{array}{c}k_{\text {biol }} \\
\left(\mu g^{1-n} \cdot L^{n-1} \cdot d^{-1}\right)\end{array}$ & $\mathrm{n}$ & $\begin{array}{c}k_{\text {biol }} \\
\left(\mu g^{1-n} \cdot L^{n-1} \cdot d^{-1}\right)\end{array}$ & $\mathrm{n}$ \\
\hline Codeine (CD) & - & - & 0.792 & 0.9 \\
\hline Cyclophosphan & 0.012 & 1.7 & $5.28 \mathrm{E}-04$ & 1.9 \\
\hline Ifosfamide (IF) & 0.192 & 1.3 & \multicolumn{2}{|c|}{ no biotransformation } \\
\hline Sulfamethoxazı & 0.048 & 1.6 & 0.024 & 1.6 \\
\hline
\end{tabular}


17

\section{ACCEPTED MANUSCRIPT}

85

86

Table 7. Required duration to achieve $95 \%$ removal of the selected pharmaceuticals for both activated sludge.

\begin{tabular}{|c|c|c|c|c|}
\hline \multirow{3}{*}{ Molecule } & \multicolumn{3}{|c|}{ sMBRe/municipal } & \multirow{3}{*}{$\begin{array}{c}\text { sMBRe/municipal } \\
\text { WWTP } \\
\text { t95\% bio (h) }\end{array}$} \\
\hline & sMBRe/OWW & WWTP & sMBRe/OWW & \\
\hline & t95\% max (h) & t95\% bio (h) & t95\% max (h) & \\
\hline Codeine (CD) & 16 & 22 & - & 94 \\
\hline Cyclophosphamide (CP) & 170 & 212 & 408 & 4849 \\
\hline Ifosfamide (IF) & 44 & 619 & 61 & Never \\
\hline Sulfamethoxazole (SM) & 57 & 86 & 150 & 336 \\
\hline
\end{tabular}

87 
18

\section{ACCEPTED MANUSCRIPT}

89 Table 8. Removals of the selected pharmaceuticals for both activated sludge at the average HRT of 29h of the 90 sMBRe pilot treating OWW.

\begin{tabular}{lcccc}
\hline & \multicolumn{2}{c}{ sMBRe/OWW } & \multicolumn{2}{c}{ sMBRe/municipal WWTP } \\
\multicolumn{1}{c}{ Molecule } & $\begin{array}{c}\text { Max removal } \\
(\%)\end{array}$ & $\begin{array}{c}\text { Bio removal } \\
\text { Codeine (CD) }\end{array}$ & $\begin{array}{c}\text { Max removal } \\
(\%)\end{array}$ & Bio removal \\
Cyclophosphamide (CP) & 99.6 & - & 98.6 & 67.0 \\
Ifosfamide (IF) & 58.8 & 46.0 & 42.9 & 13.7 \\
Sulfamethoxazole (SM) & 88.6 & 91.8 & 71.5 & 34.0 \\
\hline
\end{tabular}

91

92 
(i) Acclimated sludge allowed for a 34\% increase in the degradation kinetic constant

(ii) Acclimated sludge allowed an increase in the minimum inhibition concentration.

(iii) Sorption of pharmaceuticals onto sludge proved minor in comparison of biosorption

(iv) Removal of pharmaceuticals is attributed to developed biotransformation

(v) High removal factor for 5-FU whatever the presence of other inhibitory compounds 